Original Research

\title{
Hydrogen Storage in Cryogenic, Cybernetic, and Catalytic Vessels for Transport Vehicles
}

\author{
Ernest llisca 1, 2, *
}

1. Université de Paris, Matériaux et Phénomènes Quantiques, CNRS, F-75013 Paris, France; E-Mail: ernest.ilisca@gmail.com

2. Storage of Hyperfine Hydrogen for Transport, SHYT, F-75013 Paris, France

* Correspondence: Ernest Ilisca; E-Mail: ernest.ilisca@gmail.com

Academic Editor: Alfonso Chinnici

Special Issue: Hydrogen Energy: Sustainable Production, Storage and Utilisation

Journal of Energy and Power Technology

2021, volume 3 , issue 4

doi:10.21926/jept.2104045
Received: June 18, 2021

Accepted: September 22, 2021

Published: October 29, 2021

\begin{abstract}
Most of the hydrogen storage vessels meant for vehicles to run the electric motor via a fuel cell during transport are designed for drives of only a few tenths of kilometers per day. The present report, however, describes a vessel model that is conceived to hold the hydrogen energy only for short periods during transport, such as a few hours. This would include transport via a light-duty vehicle, a taxi, or a bus, which would load liquid hydrogen at a station every morning for the day. This is a simple model based on the novel concept of Double Open Vessel (DOV), in which the liquid $\mathrm{H}_{2}$ is loaded inside an open container inserted inside another open container. The walls of this DOV are constituted of simplified linings that allow the entry of thermal heat nearly a hundred times greater than that allowed by the cryo-compressed vessels with higher insulation. After loading, the liquid evaporates, while the gas flows around its initial container into which it was loaded, passes through a few porous plugs, and is gradually released towards the Fuel Cell (or toward an ignition motor). Such a counter-flow of the gas creates a retroaction effect that insulates the inner container, thereby delaying the increases in temperature and pressure. The successive porous plugs installed in the space between the two containers form a system of barrages that regulate the gas flow through
\end{abstract}

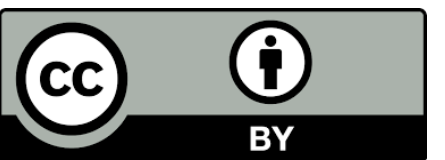


successive expansions of decreasing pressures. In addition, these catalytic plugs convert a portion of the loaded hydrogen into its ortho variety, acting as a heat pump, while temporarily storing the other portion. Collectively, these effects maintain the internal pressures below 150 bar. The proposed design for the DOV models is convenient to manufacture and has a lighter weight, and consequently, a low cost.

\section{Keywords}

Hydrogen energy; hydrogen storage; hydrogen catalysis; hydrogen for transport

Hydrogen is a versatile, storable, sustainable, and universal carrier of carbonless energy [1, 2]. One of the major fields of application of hydrogen is the automotive sector for addressing the twin threats of petrochemical resource depletion and extreme climate change conditions. Another important application is the efficient conversion of hydrogen energy into electricity using energy fuel to propel Fuel Cell Electric Vehicles (FCEVs) [3, 4].

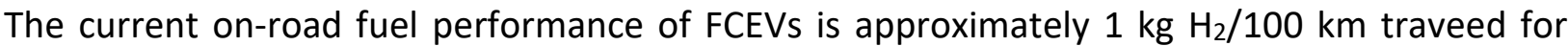
drives in the range of $500-1000 \mathrm{~km}$. Therefore, the FCEVs are capable of providing the mobility service of conventional cars along with being efficient as a form of collective transportation, such as trucks, trains or buses, naval or aerials, etc. However, a predominant barrier limiting the widespread application of the FCEV technology is the concern of the on-board storage of hydrogen [5-11].

Therefore, the present study proposes a model of hydrogen vessel, termed as a DOV (Double Open Vessel), for loading and storing liquid hydrogen in commercial hydrogen-powered FCEVs, where it would be either connected to the electric motor or directly to the internal combustion engine (referred to as the ICE model). The incorporation of the proposed vessel model as a part of hydrogen production and distribution, however, requires overcoming various scientific and technological challenges and fulfilling several economic and ecological requirements. Moreover, what is referred to as green production, currently requires huge amounts of electricity to electrolyze water, although future technologies such as solar UV light-based and nuclear devices are hope in this direction [12]. In addition, storage of huge volumes of fuel might result in the reduction of the fuel due to chemical transformation, liquefaction processes or dilution in the metallic scourers. Therefore, fuel distribution through gas networks or via trucks deliveries appears feasible. In such a case, the number of fuel loading stations becomes an important factor for the large-scale efficient distribution of hydrogen energy.

The on-board hydrogen storage in automobiles may be achieved by following three major conceptual approaches: (1) gas compressed to high pressures ( $\mathrm{CGH}_{2}$, e.g., 350-700 atm) [13, 14], (2) absorption of the hydrogen gas within porous solids [15], or (3) cryogenic liquid hydrogen $\left(\mathrm{LH}_{2}\right)$ at temperatures close to its boiling point (20.3 K [16]). However, each of these approaches has certain fundamental limits of volume, weight, or insulation. While the hydrogen stored as a compressed gas occupies a relatively large volume, absorption within porous solids adds significant weight, cost, and thermal complexity to the onboard storage systems. Liquid hydrogen $\left(\mathrm{LH}_{2}\right)$, on the other hand, evaporates rapidly during delivery, transfer, and refueling. In addition, $\mathrm{LH}_{2}$ absorbs heat from the environment while storage, causing it to pressurize rapidly during the on-board storage (which 
typically requires venting after every 3-5 days of inactivity to relieve pressure in an automotive storage configuration).

Furthermore, the storage vessel models for hydrogen-powered vehicles must compete strongly with the currently used petroleum fuel vessels. The selection of the best-performing storage model is based on two main criteria volumetric and gravimetric. Since the fuel volume has to be maintained below a certain level, liquid or compressed gas forms are essential requirements. Moreover, the vessels should perform well in terms of high insulation and strong mechanical containment against the high internal pressures. Therefore, heavy and expensive multi-layer linings and sophisticated safety devices are necessary components for these vessels. The selection of a hydrogen storage technology also relies on the factors related to fuel production and distribution as well as on several social and economic parameters. In addition, the chemistry and physics of these approaches would be different for each different application scenario. In this regard, the following text includes several reports and realizations of the Lawrence and Livermore and the Sandia National Laboratories of California (referred to as the "LLNL" hereafter) as reference.

In the period between 2002 and 2008, successive prototypes of cryogenic-capable pressure vessels were installed on-board in different successive vehicles, including the following: Ford Ranger pick-up truck powered by a hydrogen ICE [17], Toyota Prius powered by a hydrogen hybrid engine [18], and BMW on a customer ICE vehicle [19]. These vehicles registered determinant signs of progress in terms of the thermal endurance and long dormancy of the storage systems, thereby demonstrating the efficiency of cryo-compressed $\left(\mathrm{CcH}_{2}\right)$ hydrogen vessels. The key concept considered by the "LLNL" is the energy absorption capacity of a vessel with a pre-set maximal vent pressure, which is represented by the vehicle's dormancy energy (expressed in Watt-days) relative to the rate of heat transfer (Q) from the environment. Therefore, the conventional models, which were designed to hold the energy for weeks, mainly for application in personal cars, were required to have thick and heavy envelopes for greater insulation and pressure containment [20].

In contrast, the DOV models are based on a pre-set storage period, such as a daily "load and discharge". The DOVs, therefore, have a combination of a high-density hydrogen storage system (cryo-compressed and/or cryo-adsorbed) and a simplified delivery system continuously feeding the Fuel Cell devices on a per-day basis for mobile applications that are consistent with the established hydrogen stations and are determined largely by the daily demands of the commercial market. The novelty of the DOV models proposed in the present study is that these are based on the concept of energy storage for a finite duration immediately after fuel loading, i.e., the duration for which the hydrogen energy is available. Therefore, in the following text, the terms "storage period" and "temporal energy availability" would be used interchangeably as these are considered equivalent for the proposed model.

The rest of the report is organized as follows. The first section discusses the concepts of DOVs in the context of the large categories of cryo-compressed and cryo-adsorptive vessels for transportations with rapid fueling (in $\sim 5 \mathrm{~min}$ ) at high densities (70-80 $\mathrm{g} / \mathrm{L}$ ) and a commercially available $\mathrm{LH}_{2}$ pump for low evaporation-caused losses. The second section provides the details of the DOV components and the hydrogen flow crossing through. The third section summarizes the thermodynamic principles underlying the regulation of the hydrogen flow in the DOV tanks. The last section relates the performance of the proposed DOV to the actual technology-and economyrelated forecasts. 


\section{Introduction to Different Cryogenic Pressure Vessels}

\section{$1.1 \mathrm{LH}_{2}$ and Cryo-Compressed Vessels}

Most of the currently existing commercial hydrogen-powered FCEVs use compressed gas storage vessels at typical pressures of 350 or 700 bar, and these vessels have been tested rigorously to meet the required automotive performance standards. At room temperature, a pressure of 750 bar is necessary to store $4.1 \mathrm{~kg}$ of hydrogen in $100 \mathrm{~L}$, while a pressure of 150 bar suffices for the storage of liquid nitrogen (77 K). In order to achieve lower costs and enhanced safety of storage vessels, it is necessary to reduce the storage pressure while maintaining a high gravimetric and volumetric density. Storage pressure may be reduced either by the effect of temperature on the density of the fuel or by means of fuel adsorption. Cryogenic vessels of the insulating "dewar" type are capable of holding extremely cold liquid hydrogen at ambient temperatures, although this would involve multiple disadvantages in terms of cost, weight, etc.. Over the last two decades, the Livermore Lawrence National Laboratories ("LLNL") have pioneered an approach that combines the different storage technologies available currently to offer the advantages of both conventional cryogenic $\mathrm{LH}_{2}$ storage and high-pressure storage, thereby developing the cryogenic high-pressure vessels (designated as $\mathrm{CcH}_{2}$ or $\mathrm{CGH}_{2}$ ) $[20,21]$. The concept is to store hydrogen in a pressure vessel capable of operating at cryogenic temperatures (as low as $20 \mathrm{~K}$ ) and high pressures (e.g., $350 \mathrm{~atm}$ ). Further studies could explore hydrogen loading at a higher intermediate temperature of $80 \mathrm{~K}$.

The cryo-adsorptive hydrogen storage $\left(\mathrm{CaH}_{2}\right)$ on activated carbons, on the other hand, was explored and developed a long time ago in the Quebec Universities, first by Chahine and Bose [22, $23]$, and subsequently by Bénard et al. [24, 25]. The adsorption of hydrogen on zeolites has also presented interesting results [26], although the observed performances remain inferior to those achieved with adsorption on carbon compounds. The best adsorption storage has been obtained with the use of novel carbon-based microporous materials [23, 27], such as nanoporous activated carbons [22, 28], single-walled carbon nanotubes [29], and metal-organic frameworks [30]. In separate studies, Zhou et al. [31] and Richard et al. [25] demonstrated that the same storage density could also be achieved at a pressure of only 60 bar if the container is filled with the pellets of superactivated carbon AX-21TM.

In another study, an interesting numerical model was developed for the evaluation of adsorbent based hydrogen storage systems, which simultaneously solved the conservation equations for heat, mass, and momentum together with the equations for adsorbent thermodynamics [32]. It was revealed that flow-through cooling could serve as an effective means for heat removal and that the contribution of pressure work could be significant, depending on the type of the adsorbent used and the charging procedure employed. Investigations on activated carbon conducted by the Canadian laboratories in collaboration with German laboratories [33-35] emphasized the unique performance of the super-activated carbon AX-21, which is now being actively considered, along with a few MOF samples, a possible sorbent candidate for the most promising results in terms of effective storage.

However, adsorption vessels are submitted to intrinsic thermal effects, which influence their dynamic behavior considerably and raise the requirement for thermal management to have a smooth operation. In order to resolve this issue, the "LLNL" developed an approach that combines the existing storage technologies to capture the advantages of both conventional cryogenic $\mathrm{LH}_{2}$ 
storage and high-pressure storage, thereby leading to the development of cryogenic high-pressure vessel models.

The cryogenic-pressure vessels comprise a high-pressure inner vessel with its envelopes composed of a carbon-fiber-coated metal, a multilayer vacuum space insulation (MLVSI), and a metallic outer jacket. The multilayer vacuum space contains numerous sheets of highly reflective metalized plastic. While the vacuum space reduces conduction and convection heat transfer, the metalized plastic sheets reduce the radiation heat transfer. This design minimizes heat transfer in all forms, leading to the highest performance of thermal insulation available so far [22]. These vessels could be fueled either with $\mathrm{LH}_{2}$ or compressed gaseous $\mathrm{H}_{2}$ (e.g., $350 \mathrm{~atm} \mathrm{CGH}_{2}$ ) or with cryogenic hydrogen at elevated pressures (designated as cryo-compressed hydrogen, $\mathrm{CcH}_{2}$ ).

The "LLNL" also developed the subsequent generations of cryo-compressed storage models with increasing performances [19-21, 36, 37]. The first generation of these cryogenic vessels installed on a vehicle (generation 1, 2003-prototype) operated at a maximum pressure of 245 bar with an internal volume of $135 \mathrm{~L}$ and an $\mathrm{LH}_{2}$ storage capacity of $9.3 \mathrm{~kg}$. The second generation of these cryogenic pressure vessels was stronger (operating at 340 bar) with a greater volume (an internal volume of $151 \mathrm{~L}$ and the outer vessel volume of $297 \mathrm{~L}$ ) and a greater fuel storage capacity (10.4 kg of $\mathrm{LH}_{2}$ ). This generation of vessels was so compact and light in weight that it met the Department of Energy's targets for weight and volume for the year 2010 in the year 2006 itself. The third generation of these vessels, which was designed and constructed in 2009, stored the same amount of hydrogen $(10.4 \mathrm{~kg})$ as the previous generation, although the whole system $(225 \mathrm{~L})$ had been constructed $23 \%$ more compact [22]. Even though the thermal insulation thickness of this generation was lower (1.5 $\mathrm{cm}$ in generation 3 vs. $3 \mathrm{~cm}$ in generation 2), the thermal endurance remains large. The generation 3 vessel installed on-board an experimental vehicle demonstrated the longest driving distance (1000 km) with a single $\mathrm{H}_{2}$ tank. In addition, it pioneered in meeting the considerably challenging DOE 2017 targets for hydrogen storage weight (5.5\%) and volume $(40 \mathrm{~g} / \mathrm{L})$.

A detailed comparative analysis of the two advanced cryogenic hydrogen storage vessels - the "cryo-compressed" and the "cryo-adsorbed" storage vessels - operating best in the temperature range of 30-100 $\mathrm{K}$ was conducted by the Livermore laboratories [20]. This comparative analysis investigated the effective increases in the onboard $\mathrm{H}_{2}$ density and dormancy due to the effects of pressure and/or sorbent materials. The operational properties (variations in the temperature and $\mathrm{H}_{2}$ content upon refueling with either single-flow pressurized $\mathrm{LH}_{2}$ or the fueling of $\mathrm{LN}_{2}$ at the temperature of $80 \mathrm{~K}$ ) were assessed for the MOF-5 and MIL-101 cryo-adsorption vessels and the $\mathrm{CcH}_{2}$ vessel system. The comparison focused on how the respective storage capacities, vessel weights, and dormancy values varied as a function of temperature, pressure, and the type of cryoadsorption material used.

In the process of single flow pressurized $\mathrm{LH}_{2}$ fueling, the temperature of the $\mathrm{CcH}_{2}$ vessel undergoes greater reduction as a consequence of its lower thermal inertia. Therefore, these systems are more suitable for operation at lower temperatures compared to the cryo-adsorption systems. The density of the cold hydrogen fluid in the $\mathrm{CcH}_{2}$ system was compared with that of the combination of cold fluid and cold adsorbent in the $\mathrm{CaH}_{2}$ system without the consideration of the "vessel age" and the possible internal heat exchangers. All densities are increasing functions of the storage pressure, and this effect increases with a decrease in temperature. The relative benefit of the sorbent material was demonstrated to reduce with increasing pressure and decreasing temperature. As a consequence, the preferred operating pressure and temperature for the sorbents 
are less than 250 bar and $77 \mathrm{~K}$, respectively. At temperatures below $80 \mathrm{~K}$, the sorbent material brings a density penalty as the skeletal structure excludes cold gas at the pressure of 350 bar. On the contrary, the optimal conditions for the cryo-compressed vessel are achieved at the temperature of $40 \mathrm{~K}$ for pressures above 400 bar.

The key concept considered by the "LLNL" is the energy absorption capacity of a vessel with a pre-set maximal vent pressure, which is represented as the dormancy energy (expressed in Wattdays) relative to the rate of heat transfer (Q) from the environment [20]. Dormancy is defined as the period during which the system may sustain the heat leak until the maximal pressure is reached, beyond which the vessel would release hydrogen. While the "LLNL" continues to use the dormancy parameter in its analyses, the commercial vehicle storages also utilize dormancy as the key parameter for $\mathrm{LH}_{2}$ vehicle acceptability.

The $\mathrm{CcH}_{2}$ and $\mathrm{CaH}_{2}$ storage models also present certain limitations and drawbacks, which are mainly related to the cost, maintenance, losses and safety concerns [38-43]. A major component of the cost (approximately $75 \%$ of the total cost of the pressure vessel) is the carbon fiber composite wrapping of the pressure vessels, which serves as a strong factor for both safety and operating pressure requirements [44-45]. The cost targets might be the most challenging ones among all kinds of DOE targets. High maintenance duties of the high-pressure cryo-pumps at the refueling stations for $\mathrm{LH}_{2}$ delivery are also expensive [46-47]. In addition, the vacuum stability necessary for the longterm (10 years) performance of the thermal insulation in a cryogenic pressure vessel is an outstanding technical challenge. Multilayer vacuum insulation, however, demands a vacuum of high quality. Moreover, typical vacuum insulation performance degrades with time [48-49].

The cryogenic capable pressure vessel for $\mathrm{LH}_{2}$ storage also presents certain issues arising from evaporation-related losses. A large portion of these issues is significantly reduced due to the highpressure capability of these vessels. However, although the vessels contain hydrogen even as it warms up and pressurizes, these evaporation-related losses accumulate with each daily short driving distance, leading to the risk of the vehicle being stranded when parked after a long period. The general perspective is to view the higher pressures that typically accompany the cryocompressed approach as a negative factor during transports with concerns of high-pressure safety.

The optimal advantages of the cryo-compressed vessels estimated and classified along the longest dormancy are important. However, dormancy is neither a scientific nor an economic criterion as it is largely based on the social practice of personal cars and short drives. Most estimations are based on the drives of only a few tenths of kilometers per day, and there is no technical or economical advantage in storing the energy inside the individual vessels for long periods, except for occasional and intermittent drives. A huge proportion of collective transport occurs via taxis, light-duty vehicles, trucks, buses, trains, and airplanes, which repeatedly load the required energy prior to each pre-set transportation, with a majority of these requiring daily reloading of energy as well.

\subsection{The Novel Dynamic Concept of Double Open Vessel}

The DOV model proposed in the present study is based on a pre-set storage period, such as a daily "loading and discharging". This model combines the high-density hydrogen storage (largely cryo-compressed, with a few cryo-adsorption ones) with a simplified delivery system that continuously feeds the fuel cell devices periodically for mobile applications. While the "hybrid" 
system in the "LLNL" vessels has both cryo-adsorption and cryo-compression phenomena occurring either simultaneously or separately at different temperatures, the DOVs provide the potential benefits of a "hybrid" system in which both cryo-adsorption and cryo-compression phenomena occur continuously and most efficiently at different moments. The DOV technology provides a combination of programmed thermal endurance and cryogenic pressure. Therefore, the resulting system design, operation, and refueling strategies essentially combine the potential benefits of high storage capacity and flexible refueling with $\mathrm{LH}_{2}$. Moreover, the DOV technology explores the relationship between the complementary performances offered by the material science and physics of the two approaches, which are currently applied either to the same hydrogen storage task to feed a fuel cell and the electric motor or directly to an internal combustion engine. In order to maintain conciseness in the present report the text ahead would focus on illustrating the storage of only 5-10 $\mathrm{kg}$ of $\mathrm{H}_{2}$, which is typical of the light (or medium) duty vehicles, thereby allowing a comparison with conventional vessels. A brief discussion on larger loads for heavy duty vehicles will be provided in the last section of the present report.

The most fundamental principle on which the DOVs are based is that the $\mathrm{H}_{2}$ flow feeds immediately and continuously after the initial loading of liquid hydrogen, the fuel cell or the ignition engine. This principle is used in conjunction with light batteries that would, for short periods, complement, regulate, or smoothen the electric production as required. The auxiliary tanks with valves complete the construction design of the device by connecting the storage vessel to the electric or combustion systems. The DOV models receive the fuel onboard the vehicle in liquid form $\left(\mathrm{LH}_{2}\right)$, while the fuel supplied to the fuel cell is in the gaseous form at an ambient temperature. The envelopes in the DOVs are similar to those typically used for the storage of compressed gases, although the insulation is relatively lower. In traditional vessels, such lower insulation would increase the heat transfers, resulting in evaporation-related losses. However, in the DOVs, the hydrogen is naturally propelled toward the fuel cell, while the external heat is continuously evacuated without any hydrogen loss. Therefore, providing thin insulation through careful vessel support suffices to limit the heat entry rate within the range of $\sim 100-500 \mathrm{~W}$, which is over 100 times the rate reached in the general prototypes. The continuous discharge of hydrogen gas maintains the internal pressures below $\sim 150$ bar. Thinner and simplified insulation implies a moderate internal pressure, a lower weight (a DOV gravimetric storage target of $10 \%$ or higher could be within reach), and consequently a lower cost.

Another concept on which the DOV model is based is the open hydrogen container, abbreviated as $\mathrm{H}$, for being loaded in liquid hydrogen $\left(\mathrm{LH}_{2}\right) . \mathrm{H}$ is located inside another larger container referred to as the retroaction $\mathrm{R}$ container, as depicted in Figure 1 below. 


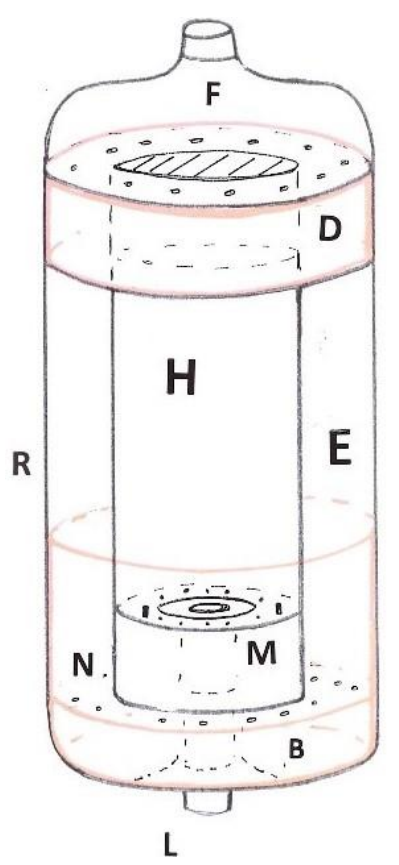

Figure 1 DOV Hydrogen Tank. H-Hydrogen Storage Container; R-Retroaction Container. $\mathrm{R}$ comprises $\mathrm{H}$ and the following components: B-Base Chamber, Support, and Compressed Storage; F-Closing and Decompressing Chamber; E-Insulating Compartment; M-Macro-porous Catalytic Plug; N-Microporous Catalytic Plug; D-MicroNanoporous Composite Plug; L-Loading Pipe.

The effusing hydrogen vapor flows out of the Hcontainer in which it had been loaded until its opposite output, thereby serving as an insulating counterflow around the $H$ container. The continuous feeding of the Fuel Cell, beginning immediately after the loading of the DOV, limits the pressure increase inside the vessel. The "compressed" and the "adsorbed" storage phases operate at different temperatures and pressures.

The open DOV is based on cryogenic, cybernetic, hydrodynamic, and catalytic properties, combining the four thermal functions currently adopted to liquefy hydrogen in the industry, although in the opposite direction (in evaporating and warming). The hydrogen is loaded in liquid form at extremely low temperatures and conveyed to the output at room temperature at a pressure of approximately 5-10 bar. The thermodynamic scheme of the open DOV may be summarized as follows:

(i) the continuous outflow evacuates a portion of the incoming heat,

(ii) the counter-flow insulates the cold reservoir,

(iii) the obstructing barrages produce successive cooling expansions,

(iv) the magnetic plugs convert a portion of the thermal kinetic heat into rotational fluxes.

\section{DOV Reservoirs}

A great variety of reservoir capacities, geometries, and shapes are available for multiple kinds of transportations. A simple DOV model with a cylindrical geometry and of intermediate capacity would be described here to explain the basic concepts and underline the complementary functions 
of the various components and the way these correlate to generate the desired pre-set energy flow. In the last section, a few extensions to different shapes and specializations to various end applications will be discussed briefly.

This section is devoted to the materials that could be used in the construction of a DOV reservoir. First, descriptions of the different compartments and their assemblage are provided. Next, the properties of the enveloping multi-layered linings are discussed from the perspective of both thermal insulation and mechanical containment. Finally, the materials used in the porous plugs, along with the available choices and the material characteristics required to achieve a programmed hydrogen flow are discussed.

\subsection{Vessel Components and Assemblage}

The different compartments within a DOV reservoir are depicted in Figure 1. In DOV reservoirs, liquid hydrogen is stored inside a cylindrical container $\mathrm{H}$, which is enclosed within the retro-action container $\mathrm{R}$ on the outside.

The initial loading of a cold hydrogen liquid, into a vessel at the environmental temperature, introduces a huge imbalance rising the pressure and thereby setting the hydrogen flow in motion. The compartments are designed to match dynamically the motion, guiding the continuous flow toward the Fuel Cell.

The inner vessel, designated as the hydrogen storage container $\mathrm{H}$, has a long cylindrical form. The lower open region of $H$ encases a porous plug $M$, which fastens a thin loading pipe $L$ that allows rapid refueling of $\mathrm{LH}_{2}$. The porous plug $\mathrm{M}$ is secured using a firm support. The superior and inferior plates of this support contain a series of holes to accommodate nozzles so as to allow the hydrogen to effuse backward continuously. The vapor then surrounds the $\mathrm{H}$ container and flows inside the enclosing envelope, as illustrated in Figure 2.

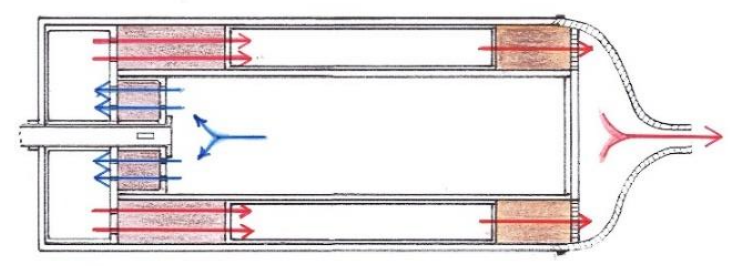

Figure 2 DOV Hydrogen Flow Path: The hydrogen current is flowing out from container $\mathrm{H}$, effusing through a series of holes or nozzles and then diffusing across the Magnetic Macroporous Plug M, allowing it to reach the Base Chamber $B$, where it would be compressed. After flowing out from $B$, the hydrogen current follows an opposite direction, diffuses through the catalytic porous plug $\mathrm{N}$, stagnates for a while in the insulated compartment $\mathrm{E}$, and then diffuses through the composite porous plug $\mathrm{D}$ until it is decompressed in the last chamber F. Finally, the hydrogen flows out toward the Fuel Cell and/or the ignition engine.

The envelope surrounding $H$, designated as the retro-action container $\mathrm{R}$, is a larger cylindric vessel designed to receive the gaseous $\mathrm{VH}_{2}$ effusing from $\mathrm{H}$ and to convey it to the outlet pipe. The 
bottom of the $\mathrm{H}$ container is first filled with the porous plug $\mathrm{M}$ and then enclosed within a cylindrical torus porous plug N. N is encased around $\mathrm{H}$ up to its inferior base. The $\mathrm{H}-\mathrm{N}-\mathrm{M}$ assemblage is depicted in Figure 3a. This assemblage is fixed on an insulating and supporting base B, filed around the loading pipe $L$, and altogether encased inside the bottom of $R$. The plug $M$ is fastened using two pierced plates- the superior plate and the inferior plate. The superior plate " $\mathrm{m}$ " has larger holes compared to the inferior plate. The base $B$ fastens the $H$ and $R$ containers to each other and also to $L$, as illustrated in Figure $3 b$.

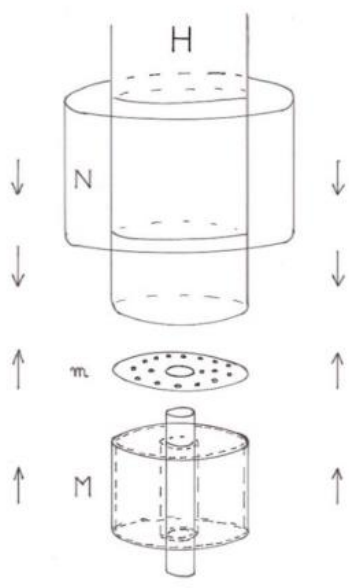

(a)

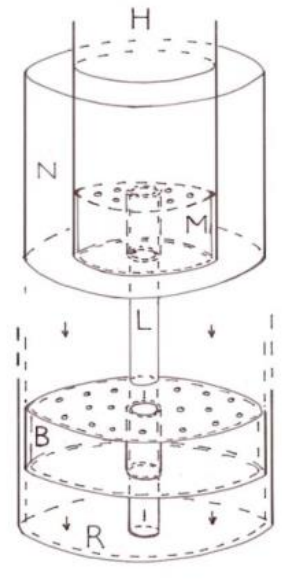

(b)

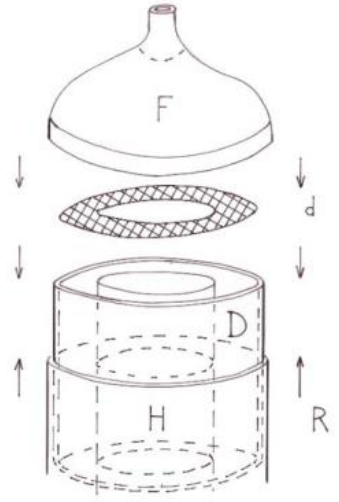

(c)

Figure 3 Assemblage of the hydrogen $(H)$ and retro-action $(R)$ containers. (a) The bottom of the $\mathrm{H}$ container is encircled by a cylindrical torus porous plug $\mathrm{N}$ up to its inferior base. After the external encasing of $N$, a supporting pierced plate " $\mathrm{m}$ " and a porous plug $\mathrm{M}$ are filled inside $\mathrm{H}$. (b) The HN-M assemblage is fixed on a pierced plate $b$, which is in turn fixed on the supporting base $B$, filed around the loading pipe $L$, and altogether encased inside the bottom of R. (c) The torus porous plug $D$ is filed and fastened around the upper part of $\mathrm{H}$. $\mathrm{H}$ and $\mathrm{D}$ are fixed together to an intermediary grid d, which encompasses, in its middle, a circular covering-plate. Finally, a conic covering top $\mathrm{F}$ closes the R container to which it is fixed, pasted, or fused after securing the outlet tube f. Finally, a firm metallic ring encircles the link at the level of the D plug.

Moreover, the base encloses a free space designed to receive the hydrogen effusing from $\mathrm{H}$ via $M$. The compartment $B$ stores hydrogen at high pressures as the current around $\mathrm{H}$ is obstructed by a few lock-gates, of which $\mathrm{N}$ is the first one. $\mathrm{B}$ is the first compressing chamber to receive the hydrogen flow and support the pressure force exerted by the hydrogen within $\mathrm{H}$.

The DOV reservoir is manufactured through the successive assembly of all its components. The pieces are fixed together sequentially, following the three steps illustrated in Figure 3c. First, the torus porous plug $\mathrm{N}$ is filed as a ring around $\mathrm{H}$, which is followed by encasing $\mathrm{M}$ inside $\mathrm{H}$. Together $\mathrm{N}$ and $\mathrm{M}$ are packed and fastened inside the base $\mathrm{B}$ and inside the lower part of the reservoir $\mathrm{R}$, around the loading tube L. Next, a torus porous plug $D$ is filed and fastened around the upper part of $\mathrm{H}$. This is followed by plugging together the $\mathrm{H}$ container and the $\mathrm{D}$ plug to an intermediary grid $\mathrm{d}$, which encompasses, in its middle, a circular covering-plate that holds and insulates the upper part of $\mathrm{H}$. 
Finally, after assembling and pasting $\mathrm{d}$ and $\mathrm{H}$, a conic top closes the $\mathrm{R}$ container after securing the outlet tube $f$ and managing an empty compartment $F$. The upper covering top overlaps slightly with the central part of the retro-action container $\mathrm{R}$ to which it is fixed, pasted, or fused. In the end, a firm metallic ring is encircled around the link at the level of the $D$ plug. The empty compartment $E$ between the $D$ and $N$ plugs is bordered by the envelope support that holds the two plugs apart. Similarly, the torus plug $\mathrm{M}$ and the base $\mathrm{B}$ are surrounded with firm support, apparent in the overall longitudinal section depicted in Figure 4. All the described components must be fitted tightly with one another to leave minimum interstitial spaces (between the compartments, supports, and plugs) that would have to be filled with a paste.

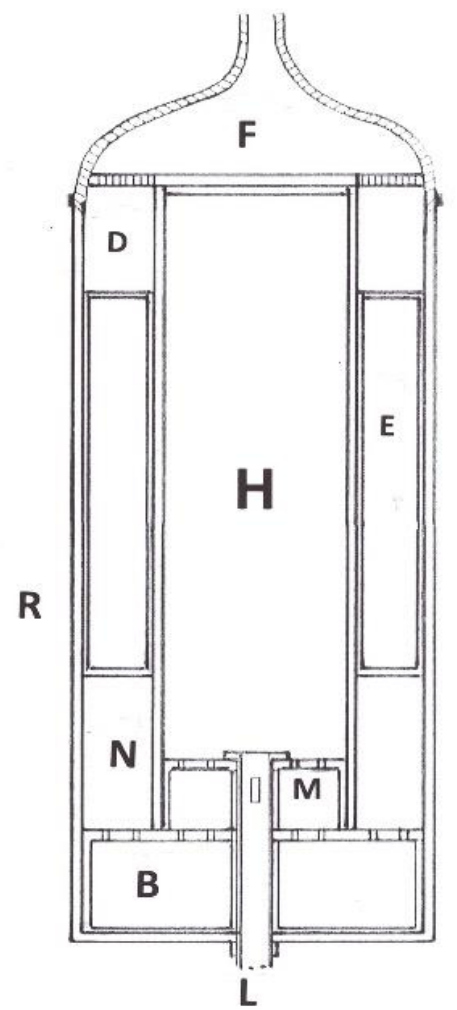

Figure 4 DOV Cross-Section: The cross-sectional view highlights the assemblage and the complementary functions of the different compartments, plugs, pipes, and supports within the R container.

\subsection{Compartments, Insulation, and Containment}

In this section, the DOV concept would be explained using a vessel model intermediate between the ones for light vehicles $(<5.4 \mathrm{~kg})$ and those that could be equipped in a truck, train, bus, or airplane. This model, referred to as the DOV 10.3 model, is designed to load $10.3 \mathrm{~kg}$ of $\mathrm{LH}_{2}$ in a total volume of $260 \mathrm{~L}$, to furnish gaseous hydrogen $\left(\mathrm{VH}_{2}\right)$ at room temperature and a pressure of approximately 5-8 bar for around $8 \mathrm{~h}$. Using this model, owing to the pre-set duty and the energy held by this quantity of hydrogen, the vehicle could be propelled for $500-1000 \mathrm{~km}$. The model could be used as part of an assembly of multiple vessels to propel, for example, a bus or a truck, which will be discussed in the last section (Section 4). The whole DOV reservoir is divided into different compartments, among which the main one is the hydrogen container $\mathrm{H}$, which receives the liquid 
hydrogen and allows the hydrogen gas to effuse all the way during the pre-set period. The gas flow path passes through the successive compartments $(H, M, B, N, E, D$, and $F)$ that partition the retroaction container. An example of the volumes and masses of these compartments is provided in Table 1 below.

Table 1 DOV Compartments: Masses and Volumes.

\begin{tabular}{llllllllll}
\hline Compartments & R & H & M & B & N & E & D & F & DOV \\
\hline Volumes (L) & 237 & 170 & 2 & 3,5 & 8 & 23 & 5 & 5 & 260 \\
Masses (kg) & 25 & 50 & 1,5 & 3,5 & 6 & 2 & 2 & 3,6 & 93,6 \\
\hline
\end{tabular}

The simple cylindrical geometry considered here has a radius of $25 \mathrm{~cm}$ and a length of $130 \mathrm{~cm}$, although it would be interesting to explore other different forms, such as a thinner and longer tube. The moderate internal pressures of the DOV models would allow new shapes and geometries. The masses of the envelopes that border and contain the compartments are essentially those of the $R$ and $\mathrm{H}$ containers, $25 \mathrm{~kg}$ and $50 \mathrm{~kg}$, respectively. The internal volumes of $\mathrm{H}$ and $\mathrm{R}$ amount to $170 \mathrm{~L}$ and $237 \mathrm{~L}$, respectively, while the external volumes, including the envelopes (liner + composite + plastics + jacket) are $20 \mathrm{~L}$ and $23 \mathrm{~L}$, respectively, which constitutes a total DOV 10.3 volume of 260 $\mathrm{L}$. The masses of the compartments include the supports in the resin-fiber composites with high mechanical performances. B and $\mathrm{F}$ also include the loading and outgoing systems. As a consequence, the total mass reaches $93.6 \mathrm{~kg}$, and the corresponding gravimetric ratio reaches $10.3 / 93.6 \approx 11 \%$, which is appreciable and beyond the DOE target. The volumetric ratio, i.e., the ratio of the hydrogen mass to the total volume is $10.3 / 260=39.6 \mathrm{~g} / \mathrm{L}$; this value is difficult to exceed without strong pressurization and, therefore, remains comparable to that for the other models.

In the case of certain models, it might be necessary to envelop $\mathrm{R}$ with an outer jacket composed of stainless steel, for example, $1.5 \mathrm{~mm}$ in thickness, and decrease the glass and polymer thicknesses by $0.5 \mathrm{~mm}$ each, resulting in the total mass of the $\mathrm{R}$ wall increasing by $13 \mathrm{~kg}$ and the global gravimetric ratio becoming equal to $10.3 / 106 \approx 10 \%$.

The materials that are crucial for the cryo-compressed hydrogen vessels are those to be selected for the container envelopes. The experimental models by the "LLNL" comprise carbon-fiber-coated metals, a multilayer vacuum insulation, and a metallic outer jacket, with the vacuum space filled with numerous sheets of highly-reflective metalized plastic. However, the DOV models aim for vessels that are lighter and inexpensive. Therefore, the linings in the DOV models do not include an inner vacuum, and consequently, their overall thermal conductivity is much larger than the vessels with higher insulation. The linings enveloping both the external R-container and internal $\mathrm{H}$ container could be prepared using multiple layers of composites glass fibers, plastics, mosses, wools, and polyesters such as polyurethane, which would eventually be metalized. The use of expensive carbon fibers is avoided for these linings.

A few representative parameters of a potential multilayer $0.8 \mathrm{~cm}$-thick envelope for the retroaction $\mathrm{R}$ container are listed in Table 2 . In this case, the total mass of the $\mathrm{R}$ wall does not exceed 25 $\mathrm{kg}$ for a surface area of $2 \mathrm{~m}^{2}$. 
Table 2 R Linings.

\begin{tabular}{lllllll}
\hline $\mathbf{R}$ & $\mathrm{r}\left(\mathrm{kg} / \mathrm{m}^{3}\right)$ & $\mathrm{l}(\mathrm{W} / \mathrm{m} . \mathrm{K})$ & $\mathrm{e}(\mathrm{mm})$ & $\mathrm{l} / \mathrm{e}\left(\mathrm{W} / \mathrm{m}^{2} . \mathrm{K}\right)$ & $\mathrm{m}(\mathrm{kg})$ & $\mathrm{s}(\mathrm{MPa})$ \\
\hline Glass Fiber & 2500 & 0,7 & 3 & 233 & 15 & 3400 \\
Polymer & 1000 & 0,05 & 5 & 10 & 10 & 500 \\
\hline
\end{tabular}

The heat transfer coefficient of the lining is obtained by combining the thermal conductivity values of the various layers of the lining, using the following expression:

$$
\frac{1}{h}=\frac{1}{k_{\text {ext }}}+\sum_{\alpha} \frac{e_{\alpha}}{\lambda_{\alpha}}+\frac{1}{k_{\text {int }}}
$$

In the above expression, $e_{\alpha}, \lambda_{\alpha}, \rho_{\alpha}$, and $\mathrm{m}_{\alpha}$ denote the thicknesses, the thermal conductivities, the densities, and the masses of the wrapping components " $\alpha$ " that are listed in Table 2 and Table 3 , while $k_{\text {ext }}$ and $k_{\text {int }}$ correspond to the external and internal border conductivities (mainly air or $\mathrm{H}_{2}$ at approximately $\left.10 \mathrm{~W} / \mathrm{m}^{2} . \mathrm{K}\right)$.

Table 3 H Linings.

\begin{tabular}{lllllll}
\hline $\mathbf{H}$ & $\mathrm{r}\left(\mathrm{kg} / \mathrm{m}^{3}\right)$ & $\mathrm{I}(\mathrm{W} / \mathrm{m} . \mathrm{K})$ & $\mathrm{e}(\mathrm{mm})$ & $\mathrm{l} / \mathrm{e}\left(\mathrm{W} / \mathrm{m}^{2} . \mathrm{K}\right)$ & $\mathrm{m}(\mathrm{kg})$ & $\mathrm{s}(\mathrm{MPa})$ \\
\hline Glass Fiber & 2500 & 0,7 & 3,5 & 200 & 16 & 3400 \\
Aluminium & 2700 & 180 & 6,35 & 28346 & 30 & 300 \\
Polymer & 1000 & 0,035 & 2,15 & 16,3 & 4 & 500 \\
\hline
\end{tabular}

The envelope of the hydrogen container $\mathrm{H}$ is wrapped around with polymer resins and also with an aluminum lining, filled with glass fibers, that strengthens at a low temperature. The envelope is

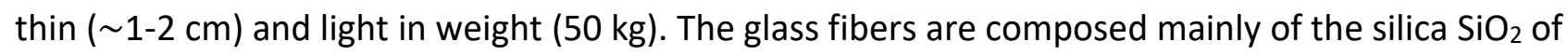
type $\mathrm{E}$, which has a high density with Young's modulus of $73 \mathrm{GPa}$. The areas of the $\mathrm{R}$ and $\mathrm{H}$ containers in the DOV "10.3" model are $2 \mathrm{~m}^{2}$ and $1.8 \mathrm{~m}^{2}$, respectively.

The total thickness of the $\mathrm{H}$ wrapping is $1.2 \mathrm{~cm}$, due to which the global heat transfer coefficient $h_{H}$ becomes equal to $3.75 \mathrm{~W} / \mathrm{m}^{2} . \mathrm{K}$ (for the $\mathrm{R}$ container, $h_{\mathrm{R}}=3.3 \mathrm{~W} / \mathrm{m}^{2} . \mathrm{K}$ ). The main relevant parameters of the $\mathrm{R}$ and $\mathrm{H}$ containers are listed in Table 4.

Table 4 DOV Main parameters.

\begin{tabular}{lllll}
\hline Containers & $\mathrm{h}\left(\mathrm{W} / \mathrm{m}^{2} . \mathrm{K}\right)$ & $\mathrm{e}(\mathrm{mm})$ & $\mathrm{M}(\mathrm{kg})$ & $\mathrm{P}_{\text {limit }}$ (bar) \\
\hline $\mathbf{H}$ & 3,75 & 12 & 50 & 258 \\
$\mathbf{R}$ & 3,3 & 8 & 25 & 203 \\
\hline
\end{tabular}

(h: heat transfer coefficient, e: thickness, M: mass and Plimit: Pressure limit)

The pressure rupture limits are calculated from the values of the constraint coefficients $\mathrm{s}_{\mathrm{a}}$ :

$$
P_{e f f}=\frac{2}{d} \sum_{\alpha} \sigma_{\alpha} \cdot e_{\alpha}
$$


The above expression is valid for a cylindrical geometry of diameter $d$. Introducing a security coefficient $k \approx 40 \%$, the limit pressure estimated from $\mathrm{P}_{\text {limit }}=k$. $\mathrm{P}_{\text {eff }}$ leads to $\mathrm{P}_{\text {limit }}=\mathrm{P}_{H} \approx 258$ bar for the $\mathrm{H}$-container and $\mathrm{P}_{\mathrm{R}} \approx 200$ bar for the R-container.

The vessels for light duty vehicles present similar gravimetric performances of $\sim 10 \%$, although their volumetric performances are lower $\sim 35 \mathrm{~g} / \mathrm{L}$. While smaller DOVs require similar cryoadsorption materials, their internal skeletal structures occupy a relatively larger space and become detrimental. On the contrary, in heavy-duty vehicles and collective transportation, such as trucks, ships, tankers, or airplanes, the volumetric ratio could become larger.

\subsection{Absorbent Materials for Porous Plugs}

The cryo-adsorption materials $\mathrm{M}, \mathrm{N}$, and $\mathrm{D}$ on the model design are to be structured using porous solids, such as activated carbon compounds [23-25, 33,34] and zeolites [26], or to be filled with powdered metal-organic frameworks [30]. The physisorption of molecular hydrogen on materials with a large surface area at cryogenic temperature has been used widely for the separation and purification of gases and also in fuel storage vessels for vehicles. Microporous adsorbents with desorption enthalpies in the range of $\sim 5-15 \mathrm{~kJ} / \mathrm{mol}$ present a variety of pores, classified as micropores $(<2 \mathrm{~nm})$, mesopores $(\in 2-50 \mathrm{~nm})$, and macropores $(\geq 50 \mathrm{~nm})[28,29,35]$.

In microporous adsorbents, a large portion of the pore volume might be filled with molecules that are attracted to these spaces due to the absorbing pull from the solid. In such cases, the absolute adsorption isotherm corresponds to the total uptake within the pores. On the other hand, the excess adsorption isotherms of mesoporous and macroporous adsorbents provide information regarding the relative number of molecules attached to the pore surfaces. The pore size distribution of a cryo-adsorption material, therefore, reflects the total density of the adsorbate molecules and not the total number of molecules within the plug.

Several scholars studied the best porous materials capable of storing significant quantities of hydrogen for application in vehicles. In separate studies, Zhou et al. [31], Xu et al. [27], and Paggiaro $[33,34]$ revealed that the gravimetric density of activated carbon adsorbents reached $9 \%$ with a volume efficiency of $17 \mathrm{~g} / \mathrm{L}$. Chahine and Bose compared the adsorption of hydrogen on different activated carbons and zeolites [23-24], while Richard et al. [25] investigated different microporous materials, such as nano porous activated carbons, single-walled carbon nanotubes [29], and metalorganic frameworks [30]. In addition, Chahine and Bose demonstrated that a storage density value comparable to the one documented for pressure vessels could be reached at a pressure of just 60 bar if the container is filled with the pellets of super-activated carbon AX-21TM.

The activated carbon microporous materials AX-21, MOF-5, and MIL-101 have cage-like porous structures, rendering these better as adsorbents for hydrogen compared to zeolites with sorbent densities between 0.15 and $0.51 \mathrm{~kg} / \mathrm{L}$. The performance of AX-21, MOF-5, and MIL-101 is even better than that of the regular-grade activated carbons [20]. The surface areas of AX-21, MOF-5, and MIL-101 are of the order of $3000 \mathrm{~m}^{2} / \mathrm{g}$, while those of regular-grade microporous carbons are between 700 and $1800 \mathrm{~m}^{2} / \mathrm{g}$. The gravimetric density of hydrogen is approximately $100 \mathrm{~g} \mathrm{H}_{2} / \mathrm{kg}$ of adsorbent, and its volumetric density is approximately $32 \mathrm{~g} \mathrm{H}_{2} / \mathrm{L}$ in AX-21 carbons at $77 \mathrm{~K}$ and 50 atm. The volumetric density of the hydrogen adsorbed on AX-21 is much lower than that of any of the idealized slit pores, reflecting the low density of activated carbon $(\sim 0.3 \mathrm{~kg} / \mathrm{L})$. 
The preferred operating pressure for these sorbents (AX-21, MOF-5, and MIL-101) is less than 250 bar, a regime that utilizes the density benefit of the cryo-adsorbent prior to the exclusion density penalty becoming too large. In all sorbents, the stored hydrogen density is an increasing function of the storage pressure, with the effect increasing with a decreasing temperature. The adsorbent efficiency correlates with the specific surface area per unit volume of the adsorbent $(\epsilon$ $\left.0.2-1.5 \mathrm{~m}^{2} / \mathrm{L}\right)$ defined by the product specific surfaces $\left(\in 1.4-2.8 \mathrm{~m}^{2} / \mathrm{kg}\right) \times$ densities $(\in 0.15-0.51$ $\mathrm{kg} / \mathrm{L})\}$.

With such performances, the porous plugs $\mathrm{M}, \mathrm{N}$, and D may store a maximum of approximately $5 \%$ of the hydrogen mass in the micropores, while around the same quantity flows continuously through the larger macropores. In the described model of $10.3 \mathrm{~kg} \mathrm{H}_{2}$, the plugs would contain a maximum of $2 \times 500 \mathrm{~g}$ of hydrogen (approximately 10\%). The first plug $\mathrm{M}$ would have the largest percentage of macropores, approximately $25 \%$ of the total volume, to facilitate the first discharge. The successive plugs along the current direction, $N$ and $D$ and so on, would have an increasing number of meso- and micro-pores with an increasing function of retention. In regard to the weight estimations listed in Table 1, approximately $10 \%$ by weight concentration of magnetic oxides was included in the carbonaceous plugs.

Wang and Johnson [32] performed the molecular simulation of hydrogen adsorption on singlewalled carbon nanotubes and carbon slit pores with diameters ranging from $\sim 6 \AA$ to $20 \AA$ at Pittsburgh. The simulation was performed at temperatures of $77 \mathrm{~K}$ and $298 \mathrm{~K}$ and the pressure range of 1-100 atm. The simulation revealed that the materials were able to hold either one or up to five layers of adsorbed hydrogen. It was observed that the smallest pores held the most hydrogen on a per weight basis and per unit volume throughout the pressure range in which the simulation was performed. The smallest slit pore held a single layer of hydrogen, the highest uptake at the lowest pressures due to its strongest solid-fluid interaction potential.

However, at the higher pressures, the wider pores exhibited a higher storage capacity. At $77 \mathrm{~K}$, the total amount of hydrogen adsorbed within the smallest pores remained constant throughout the pressure range and rapidly reached a value of $0.3 \mathrm{~cm}^{3} / \mathrm{m}^{2}$, which was close to the experimentally observed monolayer coverage of $0.32-0.35 \mathrm{~cm}^{3} / \mathrm{m}^{2}[50]$. In contrast, the two largest pores were not filled completely even at the pressure of $100 \mathrm{~atm}$. It was, therefore, clear that the optimum pore size for hydrogen storage depended on the storage pressure. At pressures greater than approximately $5 \mathrm{~atm}$, the larger pores exhibited higher effectiveness because the weight fraction was dominated by the amount of available pore space at higher pressures. The storage capacity was much lower at $298 \mathrm{~K}$ compared to that at $77 \mathrm{~K}$. At $298 \mathrm{~K}$, the smallest pore was not filled completely even at the pressure of $100 \mathrm{~atm}$, and the amount of adsorption was lowered by a factor of 6 (roughly) for the small pores. The gravimetric density increased with the pore width. This was because, at this high temperature, the pore volume tends to be more important than the solid-fluid interaction potential.

However, such a description of the pore fillings must be tempered in the perspective considered in the present study as the thermodynamic conditions of the DOVs differ from those in the above described quasi-static measurements. The porous plugs of the DOV models are not designed to operate at the equilibrium quantities of adsorbed hydrogen, and their main function is to rather regulate the hydrogen flow at constrained fillings of the micro-and nano-pore conditions under the high pressures of the adjacent compartments. The flow rate is initially governed by the pressure gradient between the $\mathrm{H}$ container and the outlet condition. The relative number and size of the 
pores are utilized to limit the flow rate rather than to increase the number of sorbed molecules. Hydrogen is retained when the pressure of the adjacent compartments is high and released when the pressure declines to sustain the flow. Therefore, the partial and transient filling of the pores is considerably different from that observed in equilibrium conditions and demonstrates a higher correlation with the flow obstruction caused by the plugs.

The microscopic observation of the kinetic molecular sieving of the hydrogen isotopes in a nano porous material [51] revealed that the experimental diffusivities of $\mathrm{H}_{2}$ matched reasonably with those obtained in the simulations conducted with a pore width that decreased with increasing temperature. It was concluded that at the lowest temperature $(30 \mathrm{~K})$, diffusion is governed by the transport through wider pore mouths because the associated energy barrier is relatively low. However, the higher kinetic energy with an increase in temperature leads to an increase in the contribution of the narrower pore mouths, leading to higher energy barriers.

The DOV plugs present an additional complexity: the magnetic plugs $M$ and $N$ have the complementary and essential function of catalyzing and converting the hydrogen to thermal proportions as those hydrogen liquefiers [52]. NBS laboratories and Gas companies were the pioneers in extensively studying the commercial ortho-para converters and selecting these for their efficient performances in the hydrogen conversion [52-55]. These converters comprise the $3 d$ transition metal powdered magnetic oxides (iron, chromium, or nickel) diluted, impregnated, or dispersed inside the selected porous frameworks [56-59]. These are now available as inexpensive commercial standards. The industrial hydrogen liquefiers require important catalytic steps in successive stages to cool the hydrogen to a pure para form [60-65]. DOVs, on the other hand, utilize the converters in the opposite direction to increase the ortho form concentration, thereby utilizing them as heat pumps.

Since the beginning of this century, novel catalysts have emerged, and their properties are being studied using novel radiative methods in research laboratories [66]. A few of these catalysts are magnetic, in the form of self-supported iron or chromium oxides $[58,59]$ or multiple-decked sandwiches [67], dispersed inside a porous zeolite [57], or attached to a MOF structure [68-69]. Recently, studies have reported novel magnetic [70] or non-magnetic [71-75] nanocomposites and topological surfaces.

Advances in molecular surgery have led to the development of novel techniques for open ligands in the MOF or carbon structures [30,76]. The pore size and hydrogen volumetric density optimization enable inserting another adsorbate surface within large-pore MOFs. This is achieved through impregnation with a non-volatile guest or catenation with another similar framework. It has been demonstrated that large molecules such as $C_{60}$ may be inserted into MOF-177 from the solution phase (the large pores in MOF-177 have a diameter of $11.8 \AA$, which is sufficiently large) [77]. Besides reducing the free diameter of the pores, such guests provide additional adsorptive sites, thereby promote the catalytic efficiency of the structure.

Rowsell and Yaghi were the first ones to describe these novel approaches for impregnation with reactive species through coordinative unsaturation [30]. This is possible with metal clusters that have additional terminal ligands of attractive secondary building units bound to them in certain MOFs. The solvent molecules coordinated to the metal may be liberated, and the terminal ligand may be removed without detriment to the framework, thereby exposing an open metal site to the void region. This has typically been achieved for axial ligands bound to metals exhibiting the JahnTeller distortion [78]. 
Another approach to construct MOFs with open metal sites is to embed these within a linker. Chemical modification with topology retention reported for a series of $\mathrm{Zn}_{4} \mathrm{O}$-based MOFs [79]. According to the initial studies in this regard, the length and width of the linker appear to influence the hydrogen uptake at $77 \mathrm{~K}$ [80]. A strong binding between $\mathrm{H}_{2}$ and open $\mathrm{Ni}^{2+}$ has also been observed in open framework phosphate [81], with these nickel-containing materials being particularly efficient in the ortho conversion of the hydrogen flow.

In summary, studies have revealed numerous porous materials exhibiting a variety of diffusive patterns through their labyrinthic frames. The simple activated carbons, pyrolyzed graphites, or even zeolites with embedded ionic fragments would be sufficient for the prototypes meant for immediate applications. Further complex catalytic plugs with increased storage capabilities, although already available, should be analyzed further for flow regulation and gate functions in the second stage.

\subsection{Flow and Counter-Flow: The Temporal Phases}

Let us consider the dynamic perspective of the entire flow from its origin at the $\mathrm{H}$ container up to its final exit from the R container. The flow dynamics change permanently and continuously, although four distinct successive steps may be observed. These temporal steps also correspond to the different physical phases of hydrogen -liquid, fluid, or vapor. Here onward, the term "phase" would be used for representing one particular step among all the successive evacuation steps. In a typical liquid hydrogen infrastructure, the filling of a tank usually involves the following three steps: (1) Filling, (2) Pressure Build-Up, and (3) Boil-Off [15]. In the first step, liquid hydrogen flows into the container from the trailer along a pressure gradient, causing the pressure with in the vessel to rise, despite the insulation, due to certain unavoidable heat inputs, until the maximum pressure is reached, which causes the blow-off valve to open. A portion of hydrogen is blowing out and is lost. In most procedures, the pressure increase over time during the "Build-up" step is linear [15].

In general, theoretical analyses consider the system to be in thermal equilibrium, i.e., all state variables are distributed equally throughout the system. In such a case, the system is described by the first law of thermodynamics and the law of conservation of mass for open systems. In the DOV models proposed in the present study, hydrogen does not rest at equilibrium, and a fourth step is introduced in the dynamics, -between the "Pressure Build-Up" and the "Back-off" evacuation steps - the hydrodynamic steady-flow step. The parameters of the DOV are selected such that this fourth phase is prolonged to the maximum extent possible. The four filling and evacuation steps (or phases) may, therefore, be stated concisely as follows: (I) Loading and Boil-Off, (II) Pressure Build-Up, (III) Steady Flow, and (IV) Back-off.

\subsubsection{Loading and "Boil-Off"}

Rapid refueling ( $\sim \mathrm{min}$ ) of the cryogenic pressure vessel may be accomplished at a low temperature $(20.4 \mathrm{~K})$ and high density $(\sim 80 \mathrm{~g} / \mathrm{L})$ using a commercially available $\mathrm{LH}_{2}$ pump with low evaporation-related losses.

The DOV filling tube slides inside a fixed cylinder until the apertures located on the top of the tube penetrate the hydrogen container, as illustrated in Figure 5a. In the filling process, a certain amount of gaseous hydrogen has to be transferred back from the vessel and is referred to as the back-gas. The following three kinds of losses occur during this process: the loss of input heat due to 
evaporation to lower the temperature within the pipeline and the hydrogen container; the loss of the filling volume when the gas replaces the liquid; and the pressure drop due to various restrictions and frictions within the pipeline. Therefore, the loading tube might be equipped with an adjacent return to evacuate the vapor created to cool the vessel and the pipeline during the load. Alternatively, an additional step involving a pulsed alternation of injection and aspiration might be applied until an appreciable amount of cooling (measurable in terms of economy) is achieved in the $\mathrm{H}$ container. After filling, the external heat reaches the liquid in a few minutes and causes progressive evaporation.
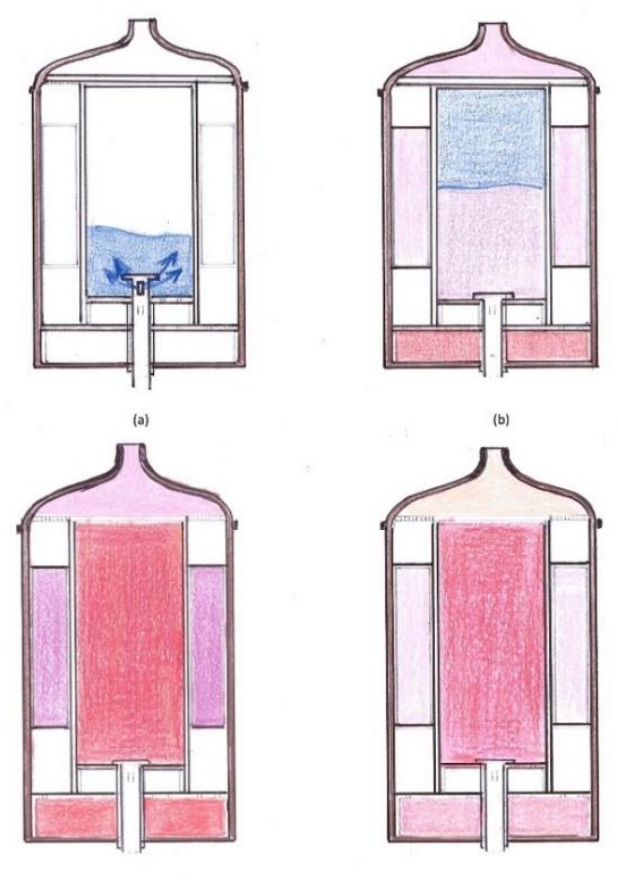

Figure 5 Temporal Phases in a DOV: The four steps of DOV hydrogen (a) filling, (b) effusing, (c) diffusing, and (d) evacuation involving the liquid, fluid, and gaseous physical phases of hydrogen alternating with and following one after the other: (I) Loading and Boil-Off, (II) Pressure Build-Up, (III) Steady Flow, and (IV) Back-off.

The volume of the H-container is selected such that it is sufficiently large to decrease the hydrogen density initially to $\sim 60 \mathrm{~g} / \mathrm{L}$. In this step, a few hundred grams of hydrogen remaining in the $\mathrm{R}$ container from the previous usage, at room temperature, are cooled by the cold $\mathrm{H}_{2}$ vapor effusing out from the container. Subsequently, the enriched flow diffuses through the various restrictions, is warmed, and finally reaches the exit flow toward the fuel cell at room temperature. Inside the $\mathrm{H}$ container, the mixture of liquid and vapor becomes turbulent, although for a short period of a few minutes only, until the completion of the first vapor evacuation. The mixture state crosses the saturation curve and becomes characteristic of a single fluid phase. The parameters are selected such that the crossing point that represents the end of that phase reached at time $t_{1}$ is as close as possible to the critical point at $\mathrm{T}_{1}=30 \mathrm{~K}, \mathrm{P}_{1}=37 \mathrm{bar}$, and $\rho_{1}=50 \mathrm{~g} \cdot \mathrm{L}^{-1}$. 


\subsubsection{Pressure Build-Up}

The flow, being restricted and regulated by the obstructing porous plugs, crosses over the successive compartments of decreasing pressures along the direction of the flow. However, all these pressures, although increasing with time in the retro-action container, are limited by the ortho spinning of the converted molecules, which absorb a portion of the external heat, and the successive expansions. Moreover, the overall warming inside the retro-action $\mathrm{R}$ container is compensated partly by feed dilution due to gas ejection which, in turn, limits the hydrogen thermal conductivity and increases the reservoir insulation.

The pressure build-up inside the $\mathrm{H}$ container, as illustrated in Figure $5 \mathrm{~b}$, increased to 120 bar after approximately one hour, while the $\mathrm{H}$ density decreased to $\sim 40 \mathrm{~g} / \mathrm{L}$. The micro-and nano-pores of the successive plugs were filled by this time, and approximately $34^{\text {th }}$ of the stored hydrogen remained inside the container at the temperature of approximately $80 \mathrm{~K}$. That phase ended with pressure saturation when the decrease in hydrogen density compensated the increase in the temperature.

\subsubsection{Steady Flow}

When the pressure $\mathrm{P}_{H}$ inside the $\mathrm{H}$ container saturated, the flow reached a quasi-steady regime, as illustrated in Figure $5 \mathrm{c}$. The catalytic action of the magnetic plugs and also the J-T expansions decelerated the pressure increase inside the various compartments. The temperature of the $\mathrm{H}$ container increased reasonably along the «built» isobar of approximately 120-130 bar. The end of the third phase occurred after half of the total energy period approximately, when the $\mathrm{H}$ density decrease had reached the value of approximately $25 \mathrm{~g} / \mathrm{L}$ and $60 \%$ of the stored hydrogen had been exhausted while the remaining portion had crossed the $150 \mathrm{~K}$ isotherm. At this time, the temperature of the flow in the $\mathrm{E}$ compartment of the $\mathrm{R}$ container was beyond $200 \mathrm{~K}$ and had even reached room temperature in the $\mathrm{F}$ decompressing chamber. The temperature gradient inside the D plug was due to the rotational excitation of the para manifold in the " $=2$ " state, which absorbed a portion of the incoming heat. Approximately $65 \%-70 \%$ of the molecules had been converted to the ortho variety, and nearly half of the remaining para molecules had been equilibrated in the excited "J = 2" rotational state.

\subsubsection{Back-Off}

When the cumulative density decrease was sufficient, the pressures in the various compartments were lower, as illustrated in Figure $5 \mathrm{~d}$. The various porous compartments desorbed, thereby absorbing a portion of the incoming heat and delaying the overall warming. The outflow rate then decreased gradually until it reached $\sim 10 \mathrm{~g} / \mathrm{min}$. The system relaxed and asymptotically reached the ambient temperature after the preset energy period of $\sim 8 \mathrm{~h}$.

\section{Flows and Dammings}

The DOV functions that influence the flow are complementary to one another, particularly those of the damming system and of the retro-action scheme. The present section first discusses the feedback effects allowed by the retro-action scheme in the DOV reservoirs. The cybernetic retroaction delays the heating of the stored hydrogen and introduces automatic self-control of the flow 
rate, thereby conferring a certain degree of stability to the system. Next, the thermodynamic properties of the hydrogen flow submitted to various restrictions (plugs, supports, holes, nozzles) are discussed. The plug dammings produce gas expansions, lowering and delaying the pressure and temperature increases. Finally, the mass and heat transfers and their consequent time delays are discussed.

\subsection{Self-Controlled Evolution by Retro-action}

The cybernetic device of a feedback loop is well recognized after the study by Wiener, Shannon, and Von Neumann [82]. This device was applied in Automatics by H. Nyquist and H. Wade Bode to study the stability of loop systems. The mechanism applied to the DOV reservoirs combines the principle of feedback control with that of counter flow cooling currently used in heat transfer devices and liquefaction procedures. The basic functions of the retro-action container include the insulation of the stored hydrogen and the control of the flow rate.

The retro-action scheme under operation in the DOV reservoirs is illustrated in Figure 6. $Q_{i}$ is the incoming heat from the environment into each compartment $i \in\{M, B, N, E \ldots D, F\}$ and $q_{i}$ is the outgoing heat from " $i$ " toward the hydrogen container. The environmental heat flowing inside the vessel is divided into two portions: one is the stored hydrogen in its $\mathrm{H}$ container, and the other is the one evacuated by the counter-flow to the fuel cell. At any moment, a part $q=\sum_{i} q_{i}$ of the total incoming heat $Q=\sum_{i} Q_{i}$ is transferred to the hydrogen container while the difference $\mathrm{Q}-\mathrm{q}$ is used to warm the hydrogen flow. Finally, the energy increase is evacuated by the outgoing flow. Therefore, $R$ has the function of delaying the heating of the stored hydrogen. The heat flows $Q$ and $q$ would be further evaluated and discussed in Section 3.3.

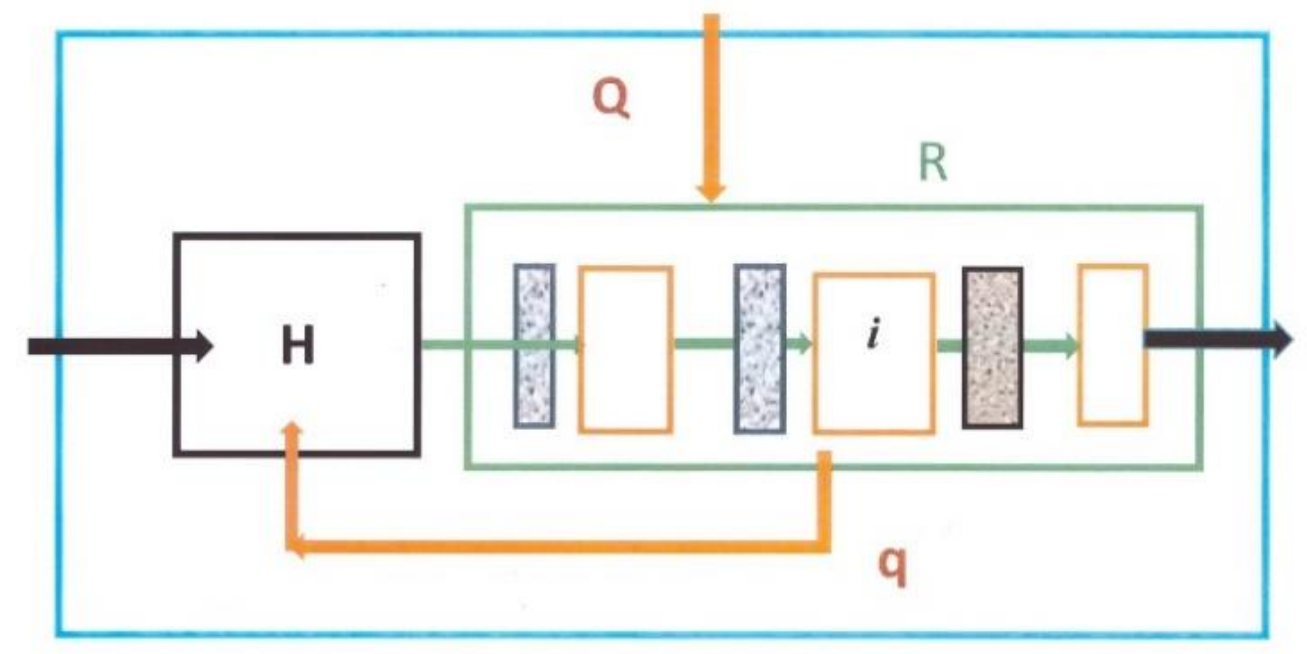

Figure 6 Heat Flows: Hydrogen follows a path that begins with effusing out of its storage container $\mathrm{H}$ into the retro-action container through successive compartments $i \in\{\mathrm{M}, \mathrm{B}, \mathrm{N}, \mathrm{E} \ldots \mathrm{D}, \mathrm{F}\}$ and then flowing out toward the fuel cell or the ignition engine. Each compartment receives the heat $Q_{i}$ from the environment and transfers a portion of it $q_{i}$ to the hydrogen container. In total, the retro-action container receives $Q$ and transfers $q$. 
DOV has a simple topology similar to that of Klein's bottle (the top being connected to the bottom). The structure comprising two connected vessels, one inside the other, confers a certain degree of stability to the system by damping the fluctuations. The retro-action container allows the crossing of two flows: heat and matter. One portion of the incoming heat flows out in the direction of the current, and the other portion flows in the reverse direction toward the current source.

If, for example, the temperature of the counter-current increases, the heat entering in $\mathrm{R}$ (in proportion to the temperature difference) decreases, which limits the heating. Moreover, the transfer to the $\mathrm{H}$ container increases, which increases the internal pressure $\mathrm{P}_{\mathrm{H}}$, thereby increasing the hydrogen flowing out and cooling the counter-current (and the reverse as well). Similar autocontrols apply for the respective $\mathrm{H}$ and $\mathrm{R}$ hydrogen flow rates and densities and also to the pressures. If, for example, the counter-current pressure increases, more hydrogen will flow out from $R$, and simultaneously, less hydrogen will flow in from the $\mathrm{H}$ container, both moderating the initial pressure increase.

The retro-action container, therefore, allows the cybernetic property to dampen the fluctuations in these variables. Although the variables vary continuously and might change abruptly on the scale of a microsecond, particularly when crossing the border between two compartments, the insulating functions of the linings and the porous plugs, as well as the retro-action control, smoothen these fluctuations, thereby resulting in a gradual variation in the state variables on the minute scale in each compartment. At any point in time, each compartment contains a definite quantity of hydrogen at a definite temperature and pressure common to that compartment. Therefore, despite the highly irreversible character of the hydrogen warming from $20 \mathrm{~K}$ to $300 \mathrm{~K}$, a certain degree of "quasi-steady-state" is established inside each compartment. They all evolve in time and also in correlation with each other, each portion of gas with another and also with the plugs, linings, and supports.

\subsection{Thermodynamics of the Damming System}

The first characteristic of the DOV-based shortterm hydrogen storage device is based on the containers apertures; the hydrogen is stored in a non-equilibrium state inside an open system that is described by the thermodynamics of irreversible processes. In order to control the flow, different successive porous plugs are included in the vessel, and the hydrogen is constrained as it has to throttle through these plugs. After the exit, at the entrance of the fuel cell, a simple membrane or a valve might be placed in conjunction with an auxiliary tank to adjust the flow.

In the model described in the present report, the three plugs $M, N$, and $D$ were introduced to illustrate the above-stated principle of the damming system, i.e., the restraining and obstructing of the counter-current flow. The number, size, and nature of the plugs are adjustable according to the desired transport function. An arbitrary number of porous rings might be placed around the $\mathrm{H}$ container. The conjugative effects of the retro-action and damming systems regulate the flow rate, and consequently, the hydrogen vapor state is represented by a thermodynamic quasistationary state defined by the state variables of mass $m_{i}(\mathrm{t})$ (and the corresponding density), pressure $P_{i}(\mathrm{t})$, and temperature $T_{i}(\mathrm{t})$, which are linked by an equation of the state, at any time $\mathrm{t}$, in each compartment. The four basic functions of the porous plugs are described briefly below.

$$
\text { "Insulation - expansion - conversion - accommodation" }
$$


Insulation: The first insulation is generated by the counterflow that evacuates a portion of the incoming energy. In addition, the plugs maintain the $\mathrm{R}$ and $\mathrm{H}$ containers farther apart and decrease the heat transfers from $\mathrm{R}$ to $\mathrm{H}$ and vice versa. This insulation is reinforced by the porous structures of the plugs. Different metal-organic frameworks, such as powders, embedded structures, and multiple-decked sandwich clusters, might be introduced to conciliate the different functions of these structures, namely, insulation, mechanical support, and abundant hydrogen impregnation. The heat flowing from the environment to the hydrogen stored in the $\mathrm{H}$-container must cross the successive insulating thicknesses $\alpha$ : the borders of the $\mathrm{R}$ - and $\mathrm{H}$-containers and the hydrogen flow between $\mathrm{R}$ and $\mathrm{H}$. The global heat transfer coefficient between the environment and the $\mathrm{H}$ container results from the following summation:

$$
\frac{1}{h_{H}}=\sum_{\alpha} \frac{1}{h_{\alpha}}
$$

Since each heat transfer coefficient $h_{\alpha}$ is selected to be $<4 \mathrm{~W} / \mathrm{m}^{2} . \mathrm{K}$, the insulation of the $\mathrm{H}$ container is reinforced by the components of the wrapped lining as well as the hydrogen counterflow.

In particular, during the initial periods, when the temperature gradient is strong, the counterflow hydrogen density and thermal conductivities are low. Globally, the heat transfer coefficient of the DOV remains equal to or below $1 \mathrm{~W} / \mathrm{m}^{2} . \mathrm{K}$, ranging between 10 and 100 times the value in actual commercial cryo-compressed devices.

Expansion: Porous plugs obstruct the flow path. It is well recognized that the isenthalpic crossing of hydrogen flow through the porous plugs produce the J-T expansions when the temperature is below $200 \mathrm{~K}$. However, in the DOV systems, the expansions are not produced due to enthalpy conservation but rather because of the continuous depletion of hydrogen due to its irreversible evacuation. Each plug plays the role of a lock gate that sluices out hydrogen progressively in time and space along the path from the storage container until the exit. The open and continuous outgoing at the Fexit together with the selected relative plug porosities construct a system of obstructing barrages with decreasing pressures in the successive $\mathrm{R}$ compartments -the highest pressures in $\mathrm{H}$ and the lowest pressures at the decompressing $\mathrm{F}$ chamber (where the pressure stabilizes around 5-10 bar).

The variations in the pressure of hydrogen with time inside the $\mathrm{H}$ container and the $\mathrm{E}$ compartment, denoted as $P_{\mathrm{H}}(t)$ and $P_{\mathrm{E}}(t)$ respectively, are presented in Figure 7. The four temporal phases are indicated in abscissa. In the Loading and Boil-Off step (I), the pressure $P_{\mathrm{H}}$ increases progressively as it is moderated by the rapid effusion of the hydrogen flowing out of its container. On the other hand, the pressure $P_{\mathrm{H}}$ increases at a much faster rate during the Pressure Build-Up step (II), almost linearly while its curve concavity turns over around the middle of that phase when approaching the 100bar isobar. Since the pressure inside the $\mathrm{R}$ container remains moderate, the presence of the adsorbent is not detrimental, and the loss in volume due to the skeletal volume of the adsorbent in the vessel is also compensated by the filling in the micro-and nano-pores. In the third step (III), a "Steady Flow" is reached when the hydrogen density has decreased below $40 \mathrm{~g} / \mathrm{L}$. In this phase, both pressures $P_{\mathrm{H}}$ and $P_{\mathrm{E}}$ remain stable. Finally, during the Back-off step (IV) of final discharge, the temperature and pressure curves inverse their concavity, the pressure relaxes and converges toward the outside and pre-set rated value defined by the fuel 
cell procedures. As visible in Figure 7, the increases and successive decreases in the pressures in $R$ and $\mathrm{H}$ exhibit a slight shift in time and intensities, which is consistent with the observation of the dependence of system dormancy on its maximum pressure reported by the "LLNL".

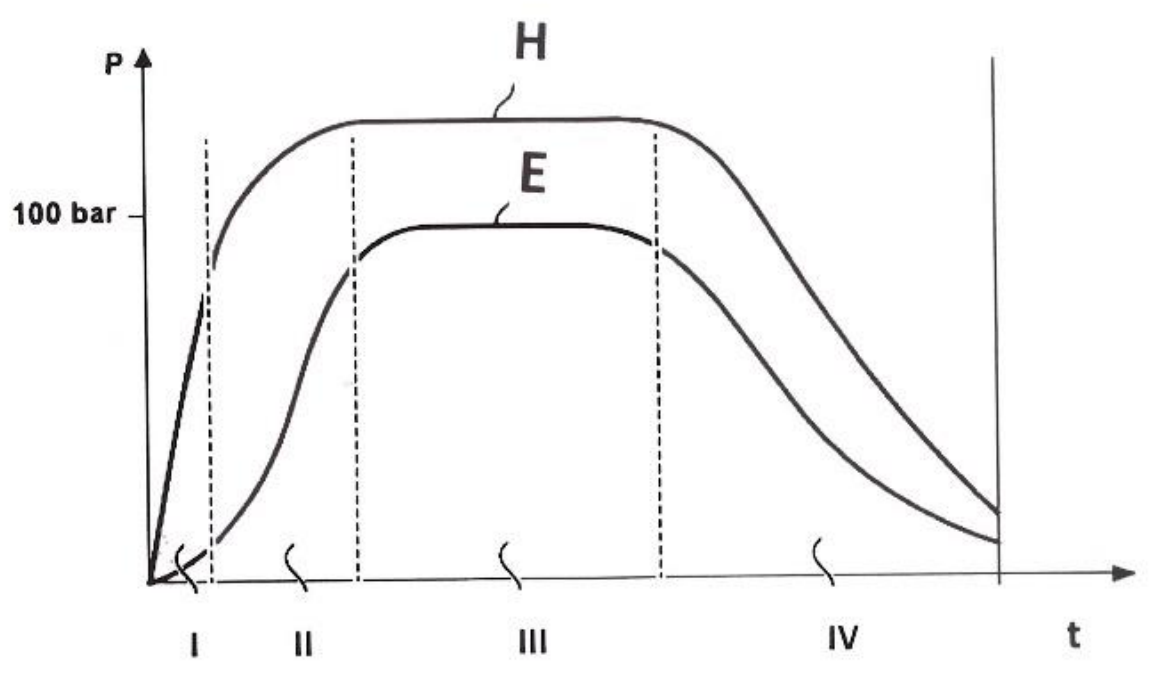

Figure 7 Hydrogen Pressures vs. time: The variations in the pressure of hydrogen with time inside the $\mathrm{H}$ container and the $\mathrm{E}$ compartment, denoted as $P_{\mathrm{H}}(t)$ and $P_{\mathrm{E}}(t)$, respectively, are different in each of the four temporal phases indicated in the abscissa. After the initial increases, $P_{\mathrm{H}}(t)$ and $P_{\mathrm{E}}(t)$ reach a plateau and relax afterwards. The pressure increase in the storage container $\mathrm{H}$ is faster and stronger compared to that in the retro-action container $\mathrm{R}$.

Conversion: The magnetic ions that impregnate the porous substrates of the obstructing plugs exert the catalytic effect on the conversion of the impinging hydrogen molecules during their random diffusion. Upon the initial loading of the liquid, hydrogen is stored in its lowest para rotational state $(\mathrm{J}=0)$. When this hydrogen diffuses through the magnetic catalytic plugs $\mathrm{M}$ and $\mathrm{N}$, a portion of the molecules are converted to the higher-energy ortho variety (The $\mathrm{J}=1$ rotational level is at $173 \mathrm{~K}$ higher approximately). Therefore, the catalytic function cools the hydrogen flow. In the first step, when the flow temperature of the molecules effusing from the Hcontainer reaches approximately $50 \mathrm{~K}$, nearly $1 / 4^{\text {th }}$ of the hydrogen molecules are converted to the ortho variety. With the increase in the temperature, a greater number of molecules are rotating, leading to greater absorption of heat from the environment until half of the molecules are converted by the $\mathrm{M}$ and $\mathrm{N}$ plugs at approximately $77 \mathrm{~K}$. Above $200 \mathrm{~K}, 70 \%$ of molecules are converted to the ortho variety by absorbing a significant portion of the incoming energy (theoretically by a factor of $3 / 5$ to the most, although at an average of approximately 40\%) [56]. When the molecules reach plug $D$, another cooling effect begins - the thermal equilibration of the ortho and para manifolds, as described below.

Accommodation: The interaction of the gaseous hydrogen with the porous solid structure leads to the following two conditions: a thermal contact between the gas and the solid and the sticking that results in partial storage. The catalytic conversion described earlier corresponds to a partial accommodation of the hydrogen gas as a whole with the $\mathrm{M}$ and $\mathrm{N}$ plugs and at their temperatures.

Higher temperatures of the hydrogen flow are reached at the level of the $D$ plug quite soon, and when the molecules reach $D$, another mechanism begins. Since the ortho-para proportion is frozen 
as $D$ is not magnetic, the hydrogen gas behaves as a mixture of two distinctly different isomers- the ortho and the para isomers - that accommodate differently to the $\mathrm{D}$ plug temperature, and the rotational states of higher energies are excited. In the range of $200-300 \mathrm{~K}$, approximately $1 / 3^{\text {rd }}$ of the para molecules are excited to the upper $(\mathrm{J}=2)$ rotational level (at approximately 500K higher), and approximately $10 \%$ of the ortho molecules are excited to the further upper $(\mathrm{J}=3)$ level. Both transitions involve heat absorption, which cools $\mathrm{D}$, thereby contributing to insulating the $\mathrm{H}$ container top. Globally, the hydrogen molecules flowing out of the retro-action container toward the fuel cell are distributed as approximately $60 \%$ ortho $(\mathrm{J}=1$ and 3$), 20 \%$ para $(\mathrm{J}=0)$, and $20 \%$ para $(\mathrm{J}=2)$ varieties.

Moreover, the thermal accommodation to the solid plugs leads to partial and transient storage of hydrogen molecules. In the initial period in which the pressures are increasing, the plugs are progressively filled with an increasing number of molecules- first in the macropores, subsequently in the preferential adsorption sites of the micropores, and finally, inside the nanostructure of the materials (high-pressure dilution). Although the adsorption releases a certain portion of heat in that initial period, the heating of the plugs due to adsorption is also balanced by a decrease in the heat entering from the environment, which is proportional to the temperature difference. On the contrary, in the final period of higher temperatures and lower pressures, most of the molecules are evacuated due to the vibration of the skeletal structure, and this desorption effect is endothermic, thereby cooling the counter-flow while attenuating the late density decrease.

The temperature variation $T_{\mathrm{H}}(s)$, illustrated in Figure 8 , is represented in the function of entropy of the stored hydrogen (per unit mass) inside the $\mathrm{H}$ container. The temperature increase, as illustrated in Figure 8a, exhibits the " $S$ " curve form. The four "temporal phases" are indicated in abscissa. While the "Loading and Boil-Off" step $(\mathrm{I})$ is determinant of avoiding a rapid pressure increase, $T_{\mathrm{H}}$ stagnates for two reasons- the external heat is delayed due to the extremely low hydrogen density of the counter-current, and the evaporation consumes energy. In the second phase, the molecular filling of the plugs limits the temperature increase to approximately $100 \mathrm{~K}$. In the third phase, the temperature $T_{\mathrm{H}}$ increases sharply and quasi-linearly along the 120-130 isobar.

Figure $8 \mathrm{~b}$ depicts the crossing of the temperature trajectory successively through the iso-density curves in the range of 40-30 g/L, illustrating the "plateau» reached by the internal pressure. When leaving this phase at approximately $130-150 \mathrm{~K}$, the temperature curve concavity turns over, and the temperature gradually relaxes to $300 \mathrm{~K}$ during the last evacuation step. 


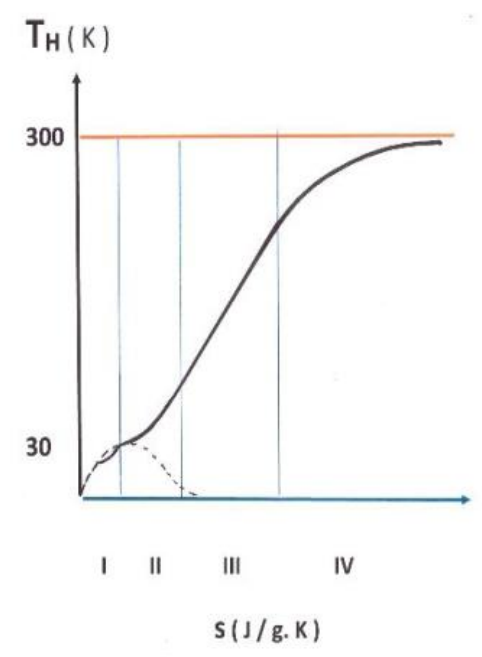

(a)

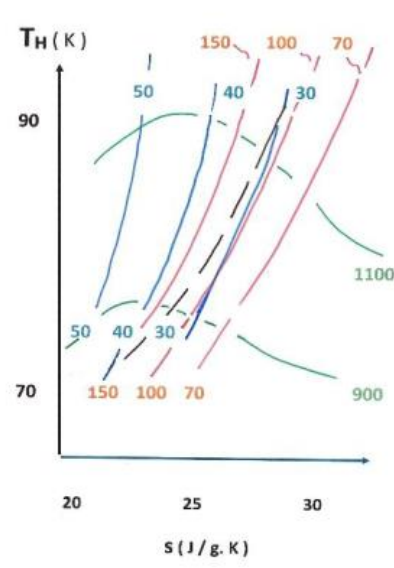

(b)

Figure 8 Hydrogen Temperature vs. Entropy. (a) The temperature $T_{\mathrm{H}}(t)$ in the hydrogen container is first delayed due to hydrogen evaporation and the insulating properties of the retro-action container $\mathrm{R}$ until it exhibits a linear increase along a pressure isobar. Finally, the temperature gradually relaxes to $300 \mathrm{~K}$ during the last evacuation step. (the four temporal phases are indicated in abscissa). (b) The temperature $T_{\mathrm{H}}(t)$ between $70 \mathrm{~K}$ and $90 \mathrm{~K}$ (dotted black line), when it crosses successively the iso-density curves of 40 and $30 \mathrm{~g} / \mathrm{L}$, and when the internal pressure starts to decrease from the 120-130 bar "plateau» in the third phase III. (the isobars are represented in red, iso-densities in blue, and iso-enthalpies in green).

\subsection{Mass and Heat Transfers}

This section discusses the DOV system in a further simplified manner by considering the average temperature of the hydrogen flow in the retro-action $R$ container, denoted as $T_{R}$. Such an average value is quite close to the temperature inside the largest compartment $E$ (as the temperatures in the smaller compartments $\mathrm{B}$ and $\mathrm{N}$ are lower and those in the $\mathrm{D}$ and $\mathrm{F}$ compartments are higher). Although such a description is elementary, it allows an initial overview of the fundamental characteristics of the system.

The combined effects of heat and mass transfers on the flow rate are due to the correlation between the retro-action and the damming effects. The mass flow induced by the imbalance between the pressure inside the $\mathrm{H}$ container and the atmospheric pressure is secured by the damming system. The successive porous plugs $p \in \mathbf{P}\{\mathrm{M}, \mathrm{N}, \mathrm{D} \ldots\}$ play the role of lock-gates and establish a descending staircase of decreasing pressures in the successive vapor compartments $v \in$ $V\{H, B, E, F\}$. Simultaneously, an ascending staircase of temperatures is established in the compartments $v$ along the direction of the flow (and in time).

Let us denote the hydrogen mass in the compartment " $i$ " at time $t$ as $m_{i}$ and the hydrogen mass flowing out from " $i$ " per unit time as $\mu_{i}$. Then, by considering the adjacent compartments $(p, v)$, the hydrogen mass conservation is expressed as follows: 


$$
d\left(m_{\pi}+m_{v}\right)=\left(\mu_{v-1}-\mu_{v}\right) d t
$$

The hydrogen mass $m_{\pi}$ in the plug $\mathrm{p}$ is a summation of various molecules, including those flowing through and those "wandering" in the micro-and nano-pores. Roughly, $\mathrm{d} m_{\pi}$ is positive in the initial phases when the plugs load a certain amount of hydrogen, negligible during the quasi-stationary third phase, and negative in the final phase. The mass balance $-d m_{H}=d m_{R}+\mu_{S} d t$ indicates that all the hydrogen molecules issuing from $\mathrm{H}$ are either stored temporarily in the retro-action container or evacuated toward the fuel cell.

The set of equations linked to one another constitute a chain beginning at time $t_{1}$, at which the stored mass $\mathrm{m}_{H}\left(\mathrm{t}_{1}\right)=\mathrm{M}$ with $\mu_{H}\left(t_{1}\right)=Q_{H}\left(t_{1}\right)=q_{H}\left(t_{1}\right)=0$, until the hydrogen evacuation at any point in time $\mu_{F}(\mathrm{t})=\mu_{S}$, denoting the outgoing flow rate toward the fuel cell. The beginning time of the hydrogen flow $t_{1}$ would be after the first vapor evacuation when the state of the hydrogen mixture inside the hydrogen container crosses the saturation curve and exhibits the characteristic of a single fluid phase. The parameters of the containers are selected such that this crossing point is approximately at $\mathrm{T}_{1}=30 \mathrm{~K}, \mathrm{P}_{1}=37 \mathrm{bar}, \rho_{1}=50 \mathrm{~g} \cdot \mathrm{L}^{-1}$. The final state $\left(\mathrm{P}_{0}, \mathrm{~T}_{0}\right)$ characterizes the outgoing flow from the vessel at any time. $P_{0} \approx 5-8$ bar and $\mathrm{T}_{0} \approx 300 \mathrm{~K}$ are defined by the FC characteristics.

In between, the evolution of the state variables with time follows the energy conservation equation provided below:

$$
d E_{i}=\left\{h_{i-1} d m_{i-1}-h_{i+1} d m_{i+1}\right\}+\left(Q_{i}-q_{i}\right) d t
$$

In the above equation, $i \in\{\mathrm{H}, \mathrm{M}, \mathrm{B}, \mathrm{N}, \mathrm{E} \ldots \mathrm{D}, \mathrm{F}\}$ denotes one of the successive compartments arranged in the direction of the flow and $h_{i}$ denotes the enthalpy per unit mass of the hydrogen mass $m_{i}$ in the compartment " $i$ ". Each compartment $i$ is warmed by the incoming heats from the environment denoted as $Q_{i}$ and the preceding compartment $i-1$, while it is cooled by the outgoing heats toward the next compartment $i+1$ and the heat $q_{i}$ to the hydrogen container (except for the first container $\mathrm{H}$ and the last compartment $\mathrm{F}$ ). The enthalpic energies $E_{i}$ include the energies of the different components of compartment " $i$ ".

In addition to the hydrogen system $\mathrm{H}_{2}$ \{hydrogen fluid, in the pores $\}$, it is necessary to include the warming of the solids $S\{$ plugs, linings, and supports $\}: U_{i}(t)=\sum_{i} U_{i j}(t)$, where $j \in\left\{H_{2} ; \mathrm{S}\right\}$. In a "vapor" compartment $v \in \mathrm{V}=\{\mathrm{H}, \mathrm{B}, \mathrm{E}, \mathrm{F} \ldots\}: d E_{v}=\mathrm{d} H_{H_{2, v}}+d U_{S_{v}}$ includes the hydrogen enthalpy $\mathrm{d} H_{H_{2, v}}=h_{v} d m_{v}=\left(u_{v}+P_{v} \rho_{v}{ }^{-1}\right) d m_{v}$, while in a porous plug $\mathrm{p} \in \mathbf{P}\{\mathrm{M}, \mathrm{N}, \mathrm{D} \ldots\}$, the total enthalpy includes, in addition to those of the solids, the enthalpy of the interaction of hydrogen with the sorbents denoted as $H_{H \pi}$. Altogether the enthalpy of the plug $\mathrm{p}$ comprises four portions: those of the hydrogen, fluid and stored, and the warmings of the plugs and surrounding supports $d E_{\pi}=\mathrm{d} H_{H_{2, \pi}}+d H_{H \pi}+d U_{\pi}+d U_{S_{\pi}}$.

The set of "mass and energy" equations, linked to one another, constitutes a chain beginning at time $t_{1}$, until the hydrogen evacuation at any point of time, with the hydrogen variables related according to the equation of state. This leads to the variations in the temperature of hydrogen inside the $\mathrm{H}$ and $\mathrm{E}$ containers with time, denoted as $T_{\mathrm{H}}(t)$ and $T_{\mathrm{E}}(t)$, respectively; the qualitative representation of this is provided in Figure 9. 


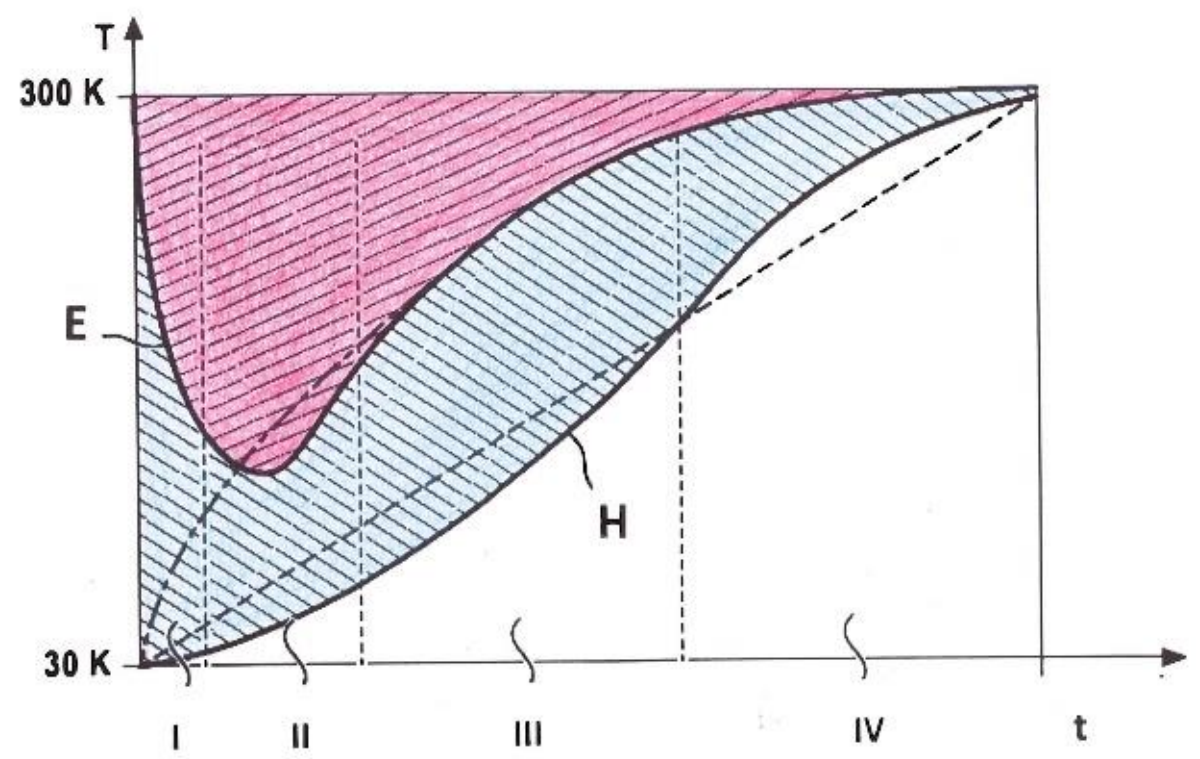

Figure 9 Hydrogen Temperature vs. time: The temperatures $T_{\mathrm{H}}(t)$ and $T_{\mathrm{E}}(t)$, representative of the four temporal phases, are indicated in abscissa. The hydrogen temperature in the retro-action container begins at $300 \mathrm{~K}$ (the wall temperature and a certain remainder from the previous usage) and then drops because of the cold hydrogen issuing from $\mathrm{H}$, although warming occurs rapidly due to the incoming heat. The hydrogen warming in the hydrogen container is delayed initially due to hydrogen evaporation and the insulating properties of the retro-action container, and later because of the catalytic and expansion effects. The incoming heat $Q$ is represented proportionally by the red area, while the transferred heat $q$ is represented proportionally by the blue area.

The four temporal phases are indicated in abscissa. The temperature $T_{\mathrm{H}}$ increases gradually during the first "Loading, Boil-Off, and Pressure Build-Up" steps (I) and (II). Subsequently, $T_{\mathrm{H}}$ stagnates due to the following two reasons: external heat is delayed, and evaporation consumes energy. The pressure inside the $\mathrm{H}$ container, $P_{\mathrm{H}}$, increases mainly because of evaporation expansion and restricted evacuation, although such an increase in the pressure implies only a moderate increase in the temperature $T_{\mathrm{H}}$ occurring because of hydrogen depletion due to both hydrogen evacuation and filling of the plugs.

In the retro-action container, the temperature $T_{\mathrm{E}}$ decreases from the level of environmental temperature due to a certain amount of hydrogen remaining in the vessel from the previous usage until it reaches a minimum value due to the counter-current cooling. In the initial phases, the filling of the plugs with molecules limits the temperature increase. A similar moderation was also observed in the thermodynamic investigation of cryo-adsorption at cryogenic temperatures by the "LLNL", which revealed that the process was quasi-isothermal.

This behavior is due to the balance between the contradictory effects of the enthalpy of $\mathrm{LH}_{2}$ vaporization, the exothermic nature of the adsorption process, the thermal inertia of the sorbent thermal mass, and the heating due to pressurization. In the third step of "Steady Flow" (III), the density of hydrogen in the porous plugs saturates, and the pressure in $\mathrm{H}$ reaches a "plateau», while 
the temperature climbs along the isobar. The concavity of the curve $T_{\mathrm{E}}(t)$ has by now turned over because the temperature in the $\mathrm{R}$ container is already high, and the flow rate has reached its highest value. The warming of the $\mathrm{H}$ container is delayed slightly as less heat is entering and the curve concavity turns around approximately at the end of the step (III), coinciding with almost half of the pre-set period. Finally, in the last step of "Back-off" (IV), involving the final discharge, all curves converge toward their outside and ambient standard values (which are defined by the fuel cell procedures).

The key parameters of a DOV are the energy storage duration $\tau$ and the hydrodynamic and thermodynamic resistances. The energy period $\tau$ is the pre-set time duration for which the hydrogen is available while feeding the fuel cell. It is, therefore, associated with the energy necessary to drive the vehicle under pre-defined circumstances. On the other hand, the incoming heat in the vessel is a function of the multi-layer composition of the linings. In general, a particular lining that wraps the retro-action container is characterized by a thermal transfer coefficient $h_{R}$ expressed in W. $\mathrm{m}^{-2} \cdot \mathrm{K}^{-1}$. When multiplied by the surface area of the lining $A_{R}$, it turns into the inverse of the thermal resistance, i.e., the conductivity $\left(A_{R} h_{R}\right)$, which was selected to be between 1 and 10 W.K. ${ }^{-1}$ for the model proposed in the present study.

According to the equation $Q=\sum_{i} Q_{i}$ and assuming a uniform heat transfer coefficient around $\mathrm{R}: h_{i} \cong \mathrm{h}_{\mathrm{R}}$, the average temperature $\mathrm{T}_{\mathrm{R}}(\mathrm{t})$ in the retro-action container could be defined as follows: $\mathrm{T}_{\mathrm{R}}(\mathrm{t})=\sum_{i}\left(A_{i} / A_{R}\right) \mathrm{T}_{i}$. However, it must be noted that $\mathrm{T}_{\mathrm{R}}(\mathrm{t}) \approx \mathrm{T}_{\mathrm{E}}(\mathrm{t})$ as $\mathrm{E}$ is the largest compartment $\left[A_{i} \ll A_{E}\right.$ for $\left.i \in\{(\mathrm{B}, \mathrm{N}, \mathrm{D}, \mathrm{F})\}\right]$ and, therefore, the temperatures of the compartments preceding $\mathrm{E}$ (i.e., $\mathrm{B}, \mathrm{N}$ ) are lower and compensate the higher temperatures in the compartments following $\mathrm{E}$ (i.e., $\mathrm{D}, \mathrm{F})$. Consequently, the heat flowing inside the vessel per unit time is obtained using the equation $d Q_{R} / d t \cong A_{R} \cdot h_{R}\left(300-T_{E}(t)\right)$, and the incoming heat that has entered during the total duration $\tau$, indicated by the slashed red area depicted in Figure 9, corresponds to the integral $\sigma_{R}(\tau)=\int_{0}^{\tau}\left(300-T_{E}(t)\right) d t$ and the equation $Q_{R}(\tau)=A_{R} \cdot h_{R} \sigma_{R}(\tau)$. Similarly, the incoming heat at any intermediate time point is indicated by the area within the borders of the vertical lines at 0 and $t$.

Let us now compare two reservoirs, both having identical envelope areas and thermal transfers, which would lead to the release of the same quantity of hydrogen in the same duration and toward identical fuel cells, although the first reservoir maintains the hydrogen temperature at $30 \mathrm{~K}$ while the other one, being equipped with a retro-action container, adjusts its temperature progressively as the heat flows inside.

The ratio of the heat entering the first reservoir to the heat entering the other reservoir, denoted as $Q_{R} / Q_{0}$, corresponds to the area ratio $\sigma_{R} / \sigma_{0}$, where $\sigma_{0}=(\Delta T) \tau=270 \tau$ is the rectangular area encompassing the figure. This surface area ratio $\theta=\sigma_{0} / \sigma_{R}$ could be considered a retro-action factor. It is clear that $\theta$ represents an amplification that is always larger than 2 and could range between 3 and 5 . Similarly, the heat transferred from the enveloping retro-action container to the Hstorage container is indicated by the red area between the curves $T_{\mathrm{E}}(t)$ and $T_{\mathrm{H}}(t)$ multiplied by the thermal transfer $A_{H} h_{H}: Q_{H}(\tau)=A_{H} \cdot h_{H} \int_{0}^{\tau}\left(T_{E}(t)-T_{H}(t)\right) d t=A_{H} \cdot h_{H} \cdot \sigma_{H}(\tau)$. At any point in time, the entering heats $Q_{H}(t)$ and $Q_{R}(t)$ would then be indicated by the areas $\sigma_{H}(t)$ and $\sigma_{R}(t)$.

Now, considering the total heat that entered inside the vessel between the initial fueling of mass $\mathrm{M}_{\mathrm{H}}$ of liquid hydrogen at $30 \mathrm{~K}$ and the final time point when all the hydrogen has flown out from the vessel at $300 \mathrm{~K}$, the variation in the internal energy of the vessel is $\Delta \mathrm{U} \approx \mathrm{C}$. 300 . $\mathrm{M}_{\mathrm{H}}$, where $\mathrm{C} \approx 11.65$ 
$\mathrm{kJ} . \mathrm{kg}^{-1} \cdot \mathrm{K}^{-1}$ considers the specific heat of the hydrogen at a constant volume and $300 \mathrm{~K}$, i.e., $\mathrm{C}_{\mathrm{v}}(300 \mathrm{~K})$ $=10.17 \mathrm{~kJ} \cdot \mathrm{kg}^{-1} \cdot \mathrm{K}^{-1}$, together with the evaporation energy of $445 \mathrm{~kJ} \cdot \mathrm{kg}^{-1}$, although it neglects the initial thermal energy that is nearly 20 times weaker. Therefore, it requires approximately $3.5 \mathrm{MJ}$ per kg to transform the hydrogen from a temperature of $30 \mathrm{~K}$ to $300 \mathrm{~K}$ under standard conditions. If that energy has been provided only through the external heat $Q_{R}(\tau)=A_{R} \cdot h_{R} \cdot \sigma_{R}(\tau) .=\Delta U \approx C \cdot 300 \cdot M_{H}$, and, therefore, with $\sigma_{R}=270 \tau / \theta$, the parameters of the thermal transfer coefficient $h_{R}$, the energy period $\tau$, the retro-action factor $\theta$, and the surface/mass ratio $a=A_{R} / M_{H}$ are linked according to the following equation:

$$
h_{R} \cdot \tau \cong \theta \cdot(C / a)
$$

The parameter ' $a$ ' in the above equation characterizes the surface/volume ratio together with the volumetric target of the DOV reservoir. The larger the vessel surface, the larger is the incoming heat and the shorter is the energy period $\tau$. In the case of the vessel model herewith described, $a \approx$ $0.2 \mathrm{~m}^{2} / \mathrm{kg}$ and $\mathrm{C} / \mathrm{a}=58 \mathrm{~kJ} \cdot \mathrm{m}^{-2} \cdot \mathrm{K}^{-1}$, based on which the above equation transforms to:

$$
\text { h. } \tau_{h} \cong 18 \theta
$$

The above period $\tau_{\mathrm{h}}$ associated with a particular $\mathrm{h}$ (in W. $\mathrm{m}^{-2} \cdot \mathrm{K}^{-1}$ ) is expressed in hours. Such an association expresses the energy conservation $Q_{R}=\Delta U$ for the DOVscharacterized by a continuous hydrogen flow induced by the heat that entered in the reservoir characterized by the DOVsurface/H-mass ratio ' $a$ ' $\approx 0.2 \mathrm{~m}^{2} / \mathrm{kg}$. The retro-action factor $\theta$ reflects the overall geometry and the porosities of the plugs, which for the models investigated here ranges between 2 and 5 . The thermal parameter ' $h$ ' is a function of the envelope wall components.

If, for example, $\mathrm{h}=4 \mathrm{~W} \cdot \mathrm{m}^{-2} \cdot \mathrm{K}^{-1}$ and $\theta=3$, the reservoir would dispense the stored hydrogen for $\tau_{\mathrm{h}} \cong 13 \mathrm{~h}$ approximately. On the contrary, if the vessel is meant for specific usage, such as for a truck delivering goods during a short period of, for example, $8 \mathrm{~h}$, an envelope thermal transfer $\mathrm{h} \cong 9 \mathrm{~W} \cdot \mathrm{m}^{-}$ ${ }^{2} . \mathrm{K}^{-1}$ would be sufficient if the retro-action parameter is slightly larger than $\theta=4$.

\section{Short-term $\mathrm{H}_{2}$ Storage for Transport}

The selection of the hydrogen storage technology for transport depends considerably on multiple processes occurring: prior to the fueling of the vehicle, during its operation, and during the stages of the downstream function of particular end-application. Open storage implies successive energy transformations (Thermal-Chemical-Mechanical-Electrical). The continuous driving forecasted in the DOV applications induces the hydrogen mass and energy extractions and transfers. The connection scheme must correlate the hydrogen flow, the fuel cell, the battery, and the electric motorization, for which the valves, sensors, and electronic control play central roles.

This section discusses how the technological and economic selections of the DOVs are influenced by the transport systems, the successive transmission of hydrogen mass and energy until its electric transformation within the vehicle, and the current status of the hydrogen production and distribution industry. First, the qualitative evaluation of the DOVs is discussed, followed by a discussion on the quantitative performance and target evaluations. Next, the model is applied to further elaborate systems adapted for various heavy-duty transportations. In the end, how the DOV 
models could provide the possible technological answers to a few economic and ecological challenges is elucidated.

\subsection{Open Vessels for $\mathrm{H}_{2}$ Storage}

The first DOV option is the cryogenic energy load, in which the hydrogen fuel is loaded into the vehicle in liquid form. This type necessitates the successive steps of Production-TransmissionDistribution up to the $\mathrm{LH}_{2}$ delivery to the refueling stations.

$\mathrm{LH}_{2}$ is often considered impractical for large-scale transportation as it is expensive and energetically intensive. However, $\mathrm{LH}_{2}$ has the advantage of overcoming the liquefaction cost and energy issues. In separate studies, Paster et al. [37] and Aceves et al. [21] analyzed the efficiency and cost of $\mathrm{H}_{2}$ production and delivery, including liquefaction, compression, distribution, and dispensing $[7,8]$. The results of both studies indicated that all forms of hydrogen delivery $\left(\mathrm{LH}_{2}\right.$ tanker truck, $\mathrm{CGH}_{2}$ tube trailer, and pipeline $\mathrm{CGH}_{2}$ ) cost essentially the same as inexpensive $\mathrm{LH}_{2}$ delivery and dispensing compensate for the high cost of liquefaction [15, 21, 60-65]. However, the hydrogen stored as a compressed gas has the fundamental limitations of volume, weight, and insulation; it occupies a relatively large volume while the materials to absorb hydrogen contribute significantly to the weight, cost, and thermal complexity of the on-board storage systems.

In terms of cost, the $\mathrm{LH}_{2}$ delivery is considerably less expensive compared to the compressed $\mathrm{H}_{2}$ delivery. This is because the $\mathrm{LH}_{2}$ tanker truck has the capacity of 7 tube trailers typically used for compressed $\mathrm{H}_{2}$ delivery, which minimizes the labor and truck capital costs. Moreover, dispensing $\mathrm{LH}_{2}$ at the station is also less expensive. The dispensing of compressed $\mathrm{H}_{2}$ warrants compressors, a cascade of high-pressure storage vessels, and possibly a refrigerator to avoid excessive vehicle vessel heating during fueling due to the compression process [83]. $\mathrm{LH}_{2}$ dispensing, on the other hand, is accomplished with inexpensive and efficient $\mathrm{LH}_{2}$ pumps, which minimizes the fueling station cost and electricity requirements [20, 21, 83-88]. While the cost of vehicle refueling is essentially equal for both, the superior density of $\mathrm{LH}_{2}$ offers a key advantage: the compact, high capacity $\mathrm{LH}_{2}$ storage enables a feasible driving range and also costs less as it requires less composite material for manufacture. In terms of the energy and ecological requirements, $\mathrm{H}_{2}$ would most probably be produced from renewable solar or nuclear electricity through the electrolysis of water in the future.

The second option is to store the hydrogen energy in a cryo-compressed vessel to feed a fuel cell alimenting either an electric motor or a combustion engine. The cryogenic pressure vessels offer the combined advantages of safe, long-range, cost-effective, and practical vehicles at a minimum ownership cost, even after including the cost of liquefaction. The generation 3 "LLNL" vessel installed on-board an experimental vehicle presented the longest driving distance $(1000 \mathrm{~km})$ with a single $\mathrm{H}_{2}$ tank while pioneering in reaching the considerably challenging DOE 2017 targets of hydrogen storage weight (5.5\%) and volume ( $40 \mathrm{~g} / \mathrm{L})$ [21].

Similar to the cryo-compressed vessels, the DOVs are loaded with hydrogen fuel in liquid form $\left(\mathrm{LH}_{2}\right)$ while the hydrogen supplied to the fuel cell is in the gaseous form at an ambient temperature. However, DOVs differ in terms of aiming for short-term $\mathrm{H}_{2}$ storage for vehicles, with regular loading and dissipation of energy. The DOVs are programmed to continuously feed the fuel cell devices on a daily basis for mobile applications consistent with the established hydrogen stations and determined largely by daily requirements. 
The optimal advantages of using cryo-compressed vessels were estimated and classified to improve and further extend the dormancy [4, 9]. However, such an approach is neither scientific nor economic and is largely based on the traditional approach of low-cost energies- the social practice of personal cars and occasional short drives. In the majority of transportations, storing and maintaining energy inside individual vessels for long periods offers no technical or economical advantages in terms of performances based on distances covered per day and service production. There is a huge proportion of collective transportation, such as light-or heavy-duty vehicles, taxis, trucks, buses, trains, and airplanes, etc., that requires repeatedly loading the required energy prior to each pre-set transportation.

The DOV tanks are open thermodynamic systems in which hydrogen flows out continuously toward the fuel cell at flow rates controlled and regulated by cybernetic and catalytic devices. This is different from the cryo-compressed vessels, in which $\mathrm{H}_{2}$ and the vessel are always at equal and uniform temperatures. In this context, the analysis here considers the consequences of open $\mathrm{H}_{2}$ storage in a vessel with a wall volume and temperature-dependent thermal mass that are not in thermal equilibrium with hydrogen, nonetheless propelling it toward the fuel cell. The DOV system implies that all stored hydrogen is exhausted after the pre-set period, except for a few hundred of grams that remain. Consequently, the DOV tanks are used in conjunction with a light battery that charges the electricity provided by the FC not used by the motor. The battery operating in parallel with the FC delivers the most when the vehicle is starting while it undergoes charging during a temporary or permanent stop.

Similar to any filling of liquid hydrogen in a vehicle tank, there is an initial heat loss during the DOV loadings due to the cooling of the hydrogen container walls. This inconvenience may be mastered if the vessel has a pressurized $\mathrm{LH}_{2}$ pump within a two-stage compression piston. If such a pump is available at the station, the vessel is cooled during the load by the low entropy-pressurized hydrogen inflow without causing the $\mathrm{LH}_{2}$ to vaporize [43].

The DOV models combine the advantages of high-density hydrogen storage with a few cumulating advantages of the absorbing materials and the counter-current cooling effect. In the liquefaction procedures, the counter-current cooling and the multi-stage conversion processes are well recognized [89-93], although these are used, for transport applications, in the opposite direction to delay the evaporation, warming, and pressurization steps. The chemical operation involved in the catalyzed o-p conversion and the mechanical operation involved in the successive expansions introduced by the damming system, in the DOV systems, are necessary for delaying and regulating the gaseous flow as a function of the daily driving distance and the vessel design pressure. These characteristics reduce the internal pressures and the insulation thickness and also require lower containment strength.

\subsection{DOV Performances and Targets}

This section discusses how the DOVs respond to various functions that allow the target cost reduction. A key parameter of DOV, $\tau$ is the programmed period during which hydrogen is available while feeding the fuel cell. This parameter is, therefore, associated with the energy necessary to drive the vehicle under predefined conditions and to the driven distance $d$ between two refuelings. Time and energy are linked. The stored energy $E$ (associated with the stored hydrogen mass $M$ ) relative to the period $\tau$ leads to a power efficiency $P=E / \tau$, which is dependent on the type of 
vehicular function and is a function of the DOV characteristics of thermal insulation (heat transfer $\mathrm{h})$, hydrodynamic flow restriction (retro-action factor $\theta$ ), catalytic efficiency $(\mathrm{o} / \mathrm{p})$, and mechanical containment (Plimit).

Thermal insulation: The DOV envelopes are similar to those typically used for the storage of compressed gases, although with much lower insulation. Similar to all cryo-compressed vessels and pressure vessels, the ones in the DOVs could also be wrapped with aluminum and glass fibers and surrounded by numerous sheets of highly reflective metalized plastic. In some vehicles, it might be necessary to enclose the DOV reservoir within an outer stainless steel jacket. In any case, the thermal resistance to the heat flow entering into the DOV is much lower than that when using the present vessels. In the latest models developed by the "LLNL", the insulation performance is limited to $4 \mathrm{~W}$. In a DOV model with $5 \mathrm{~kg}$ of stored hydrogen, the calorific energy stored is approximately $15 \mathrm{MJ}$. If this energy is dissipated by the vessel under the heat flow from the environment into the vessel for an approximate duration of $10 \mathrm{~h}$, the corresponding warming power is approximately 500 W, which istwo orders larger in magnitude compared to that of the vessel by the "LLNL" $[14,20,21$, $36,37]$. Such a huge difference allows various cost reductions due to suppression of the vacuum sheets between the linings, sparing the carbon fibers, lighter vessels compared to the commercially available ones (the ones with either compressed gas or sorbents or the other different cryocompressed vessels), which results in lighter vehicles with higher fuel economy. Less $\mathrm{H}_{2}$ is, therefore, necessary for achieving the desired vehicle range and reducing energy consumption. With the reduced weight and hydrogen pressure, together with the simplified linings and their assemblage, the DOV models aim to reduce the vessel cost by an order of magnitude.

Mechanical containment: Since the retro-action container delays a huge portion of heat flowing inside the vessel, the internal pressure of the hydrogen storage container is limited. The netting analyses have demonstrated that decreasing the design pressure from 700 bar to 100 bar results in a total vessel mass decrease (composite and liner) by a factor of 2.4 [39-43]. Therefore, the gravimetry of the hydrogen vessels operating at pressures below 150 bar might be over $10 \%$.

Hydrodynamic resistance: The hydrogen hydrodynamic flow rate depends essentially on the number, nature, and size of the restrictions, the relative volumes of the compartments, and the porosity of the plugs. The diffusion through the porous plugs, the subsequent J-T expansions, and the magnetic catalysis collectively complement and contribute to limiting the overall pressure increase, thereby delaying hydrogen warming and evacuation. The rate of mass transfer through the plugs is a complex function of the material (porosity, distribution of the pore sizes, surface attractivity, etc.) and the thermodynamic parameters (temperature and pressure in each compartment, heat transfer rates, etc) [89-93]. Reliable estimates are at best furnished by experimental measurements, and for the present DOV models, are derived from the liquefaction industrial cycles.

Catalytic efficiency: The homogeneous o-p conversion was considered in the LLNL experimental prototypes as the cryo-compressed tanks of these prototypes were tailored to retain hydrogen energy for long periods [94-96]. However, this effect remains quite weak for the following two reasons: (i) the nuclear magnetic moment of the ortho molecules is nearly 103 times smaller than the electronic moment, and the conversion rate is proportional to the square of these nuclear moments; (ii) the liquid hydrogen loaded in the container comprises almost $98 \%$ of the para form with no magnetic moment. On the contrary, a DOV model contains a few barrages composed of porous magnetic plugs, and there are plenty of efficient catalysts, with even the crushed coal 
presenting open ligands and electronic moments at the surface. The hydrogen molecules diffusing through these plugs are converted from the initial para form-dominated concentration into a mixture of the ortho-para varieties [55-60]. Most industrial magnetic converters have been studied and standardized in the NBS labs [97-104]. In recent years, novel efficient catalysts comprising nanoparticles inserted either in carbon, graphene, or buckyballs substrates, or metal-organic powders, or in topological structures $[70,74,75]$. This catalytic effect absorbs a significant portion of the heat, cooling the flow. In comparison to the translational kinetic motion, the rotational one absorbs nearly two-thirds of its heat [105-107]. The ortho-para ratio (o/p) reflects the deviation ofthe hydrogen mixture from the thermal equilibrium. In the DOV models, two targets are fixed. The first target is fixed for the o/p ratio of the outflow issuing from the second magnetic plug $\mathrm{N}$, which is required to reach close to 1 in the second phase, 2 in the second phase, and 2.75 in the last Back-Off evacuation phase. The second target is fixed for the para ratio $p_{2} / p_{0}$ of the outflow issuing from the third (or last) non-magnetic plug $D$, which is required to reach close to 1 (the equilibrium proportion above $250 \mathrm{~K}$ ).

Let us now focus on the important consequences of the DOV retro-action properties in terms of gravimetric and volumetric performances.

Gravimetry: The DOE 2010 target for the energy density of a hydrogen storage system (including

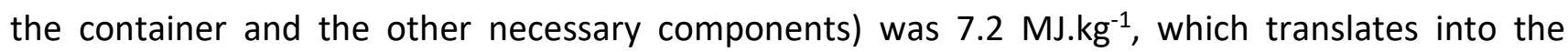
gravimetric performance (hydrogen mass/vessel mass) of $6.0 \mathrm{wt}$. \%. The target for the year 2015 was even higher, warranting a gravimetric performance of $9.0 \mathrm{wt}$. \%, which is close to the expectations of the automotive industry although this target has not yet been reached by any existing reservoir [5].

It is noteworthy that the gravimetric performance of the DOV tanks might be over $10 \%$ and, therefore, greatly oversteps the ultimate target of the US DOE. As presented in Table 2, Table 3, and Table 4 in Section 2.3, the considerably large thicknesses (approximately $2 \mathrm{~cm}$ greater than those of the $\mathrm{H}$ and $\mathrm{R}$ containers) and the insulating properties of the lining that wraps the vessel were considered to secure the performance of a possible prototype. Simpler linings with higher polymer contributions and lower thicknesses might be sufficient to reach performances of $12 \%-15 \%$ in the near future. Such performances might be easier to reach in the case of heavy-duty transportations, particularly if the reservoir volume could be extended.

Volumetry: The DOV models are able to reach a volumetric target of $40 \mathrm{~g} / \mathrm{L}$, although further improvement would be difficult as it would be difficult to delay the evaporation of the liquid for 10 $\mathrm{h}$ without dealing with high internal pressures. Therefore, the DOV models are not suited for

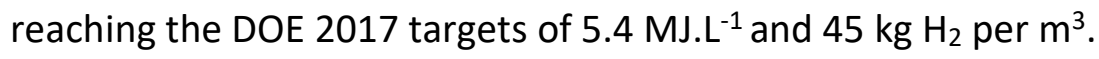

Safety: The permanence and continuity of the hydrogen gas flow within the open DOV tanks require eliminating internal regulating valves to reduce the pressure inside the reservoir, although it would require pipes and sensors to control the pressure, temperature, and tightness outside, prior to the fuel cell. An auxiliary tank might also complement the regulation chain. Electronic safety systems for monitoring the pressure, temperature, and tank filling level, along with leak monitoring and emergency stop measures developed particularly for automotive applications [2], are also important for regulation and certification. The tank systems have to undergo extensive tests and fulfill numerous regulations for pressure vessels and tank systems [16]. The DOV aperture requires avoiding a relief opening device to maintain the vessel pressure within a safe limit, thereby preventing hydrogen losses. Therefore, the number of necessary valves and sensors to be included in the transmission line is much less than that required for pressure tanks. The DOV targets must 
also distinguish what might be applicable in the present and near-future from the ones that might result from the $R \& D$ advances in the middle-term duration.

\subsection{Hydrogen Tank Systems for Mobile Applications}

This section provides feedback on the storage systems of different end applications. The hydrogen storage models differ due to the peculiarities of transportations and the different characteristics of light-duty vehicles from those of heavy-duty vehicles. Owing to low pressurization, the shapes and volumetric stages of the DOVs are relatively malleable compared to those of conventional cryo-compressed vessels, which are limited to spherical or cylindrical forms owing to high-pressure containment and surface minimization requirements.

Storage systems for automotive applications: In taxis, fleets of personal or collective vehicles, and light-duty transportations, the DOV models could be adapted to load $\mathrm{LH}_{2}$ in the range of 5-10 kg. Elongated models with a length of $2 \mathrm{~m}$ are preferred by the automobile manufacturers for installation along the vehicle's central tunnel. In light vehicles, the DOV dimensions are constrained by the limited space available. In these models, volume, weight, and cost are the critical parameters, while these are comparatively less important for heavy-duty vehicles.

Mobile storage systems for heavy transportations (trucks, buses, trains, airplanes, naval, etc.). Since these transportations necessitate holding higher energies for longer durations, it would be valuable to consider tanks with improved performances [108]. In such cases, Multiple Open Vessel (MOV) tanks, which enlarge the concept of the DOV models, reiterate the inclusion of successive retro-action containers, adapt the shapes and volumes for mobile application, and use advanced models of heat exchangers, are suitable. An example of MOV is depicted in Figure 10, in which the previously described DOV reservoir is inserted inside two successive retro-action containers, and the number of porous plugs is multiplied. Inspired by the heat exchanger models, the corresponding flow path could even be lengthened further in accordance with the volume increase. Only the outer vacuum jacket would be composed of steel, while only the inner container parameters would be calculated as a function of aluminum-lined design pressure. The separating walls in between could be constituted of synthetic material. The width of the flow path could be further extended to become much larger than that in the DOV model; the volume of the hydrogen flow path might, therefore, equal that of the hydrogen container or, at least, represent a significant fraction of it. 


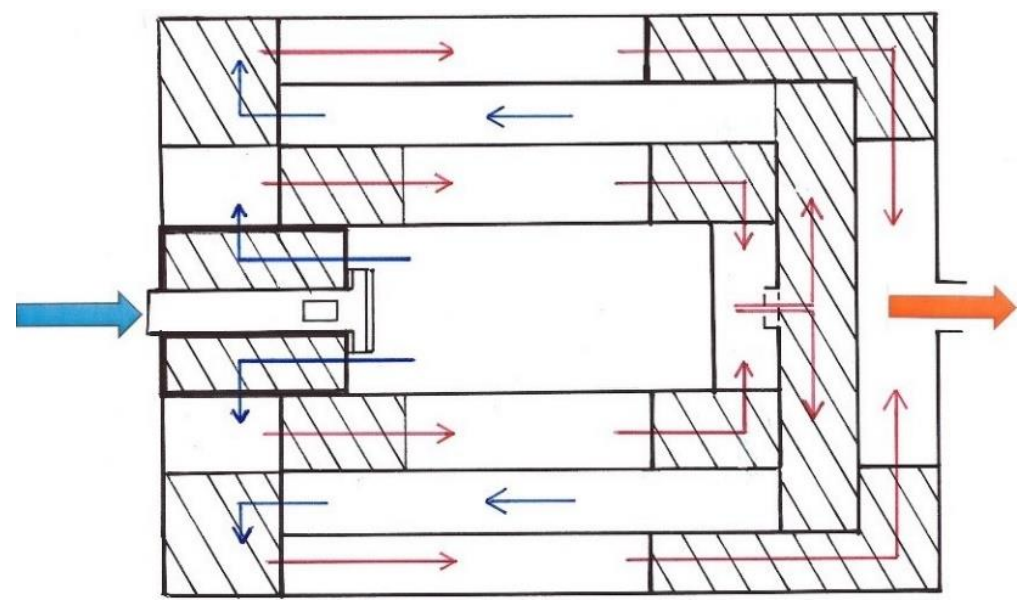

Figure 10 Multiple Open Vessel (MOV) tanks for light-and heavy-duty vehicles.

Multiple flows and counter-flows surrounding an inner hydrogen container. Such a planar cut section might correspond to a cylindric vessel, or if enlarged to 3D, one floor of a flat vessel connected by different paths to different levels within multiple reservoirs.

Multiplying the number of the adjacent flows and counter-flows would reduce the pressure differences and lower the rigidity requirements for the separating walls and their weight. As an approximate example, if the internal pressure of the hydrogen container would reach 200 bar and if it is surrounded by 10 canals, the pressure difference between adjacent flows would be 20 bar approximately. The consequent advantages in terms of containment are obvious.

Since the forms and the volumetric stages of the MOV vessels are more malleable than those of the conventional cryo-compressed vessels, they would accommodate larger external surfaces and would, therefore, be flat and elongated as the pressure difference with the environment would be much lower in these models. This property would be particularly valuable for aerial transports and would allow aerodynamic adjustments. The disadvantages of such flat forms include a higher surface/volume ratio, although adapting the surfaces of the vehicle with those of the vessel might overcome this inconvenience. Moreover, other parameters, such as the insulating factors, could be increased to compensate for the surface extension. Even curved forms are expected to become available. It is possible to combine a series of vessels of different types and volumes, particularly when the vehicle surface divides two media at different temperatures. For instance, at the bottom of an airplane, by placing a tank below that is partly in contact with the cold atmosphere and a succession of compartments above, an efficient labyrinthic flow pathway might be efficiently developed for the airplane wings.

\subsection{Hydrogen DOV Economy}

At present, over 70 million tons of hydrogen are produced every year [109]. The leading economies are now evolving plans for using hydrogen alternatives, particularly in the automotive sector. The future of hydrogen-based transportations depends largely on the successive steps of green production of hydrogen, storage, distribution, and transformation, while also ensuring that the specificities of the numerous end-use applications complement each other.

The large capacity tanks benefit from the existing infrastructures at the industrial production sites and the hydrogen liquefaction procedures have been standardized for application in spacecraft, 
which has enabled further association of the energy supply and with the energy demand, thereby enhancing the overall flexibility of the energy system. The main challenge is to develop large-scale transport and infrastructure solutions for supplying the loading sites with the necessary quantities of hydrogen required to fuel taxis, cargo trucks, passenger buses, aircraft tugs, etc.

A recent study by IEA suggests that repurposing the existing infrastructure, including the millions of kilometers of pipelines in use currently for transporting natural gas, could represent a costeffective solution. This would enable the larger quantities of hydrogen to be transported via pipeline from production sites while smaller quantities could be transported via truck. In addition, the necessary infrastructure could be developed at certain locations to support on-site hydrogen production, particularly if a renewable energy source/supply is in proximity.

The hydrogen economy in the automotive sector is forecast to grow rapidly until 2025 , crossing the inflection point in 2025. Owing to the advantages of hydrogen, such as its eco-friendliness, efficiency, flexibility, and convenience of storage/transportation, hydrogen fuel cell-based transportation is expected to become economically feasible through a gradual decline in costs via learning and economies of scale. The estimate is that hydrogen would become economically feasible when its prices come down to approximately USD $3 / \mathrm{kg}$. The roadmap of the hydrogen economy forecasts hydrogen production at a price of USD 2.2/ kg and hydrogen supply at the price of USD $4.3-4.5 / \mathrm{kg}$ by 2030 . McKinsey has predicted that enlarged "electrolyzers" and the decline in wind power LCOE (Levelized Cost of Energy and Storage) would contribute the maximum to the decline in the prices of hydrogen. As the LCOE of renewable energy has begun declining sharply recently, the production cost of electrolytic hydrogen is also expected to drop rapidly at a rate higher than the one anticipated initially.

The text ahead briefly discusses the economic advantages of the DOV hydrogen tanks in three directions: (1) rapid and flexible growth of extensive transportation networks with a limited number of hydrogen fueling stations, (2) Accordance with large-scale centralized deliveries for collective transports, (3) Adaptability to different kinds of transportations.

\subsubsection{Transportation Networks}

The commonly available on-board $\mathrm{H}_{2}$ storage vessels meant for fuel cell vehicles are aiming in the wrong direction when targeting to achieve extended dormancy (extending over weeks) for particular drives, while most of the energy consumption in the transport sector requires frequent fuelings. It is believed that the expansion of the carbonless energy $\mathrm{H}_{2}$ market would have a greater reliance on fleet vehicles, at least during its first transition period (which is expected to last up to 2050), meant for either personal or collective displacements or goods delivery.

Definite and periodic refueling is relatively correlated with the various imperatives. Fleet vehicles shall play a significant role in the market introduction phase. Refueling at a base location would allow minimizing the requirements for the necessary infrastructure and the associated costs. As a consequence of the better use of the refueling equipment and higher annual mileages achieved with a limited number of fueling stations, the fleet FCEVs would reach their economic viability earlier compared to the individually owned vehicles. Platform-based business models and "technology packaging" strategies (both human-driven and autonomous fleets based on digital algorithms) would mount the fuel cell power train on the same chassis that is used for conventional cars, although on a much larger and ecologically sustainable scale. 
Hydrogen fueling stations (HFS) represent a central element in the international programs and targets for road, naval, or aerial transports. The most frequent and economical approach to deliver hydrogen in liquid form at the station is via truck or pipes. The size of these refueling stations must correlate their number within a particular area to the number and requirements of the transport vehicles in that area. Fleet vehicles loading liquid $\mathrm{H}_{2}$ would require fewer fueling stations, and the number of such stations already targeted for the next few years would allow commencing largescale commercial programs soon and in an economically suitable manner compared to the necessary investments that would have been required for developing individual drives.

The development of the hydrogen fueling station (HFS) infrastructure is critical to the growth of the FCEV industry. Japan was the first nation to adopt a "Basic Hydrogen Strategy" in 2017. The hydrogen market in Japan is expected to grow 56-fold to a worth of $\sim \$ 100$ billion by 2030 . The increasing demand for hydrogen would particularly impact the market for hydrogen filling stations, which is expected to grow 6.5 times to a worth of $\sim \$ 300$ million by 2030 . The number of fueling stations in Japan would increase from 111 at present to approximately 581 in 2025, and then to 1.321 by 2030 . The market for FCs and filling stations is growing at a rapid pace in other nations as well. China is currently leading among all nations in adopting fuel cell buses, while South Korea reported the sale of 5,350 fuel cell-based passenger and light commercial vehicles in 2020. The European Union is also focusing on commercial vehicles, including trains, trucks, and buses.

The U.S. currently has over 45 operational retail HFSs for FCEVs, primarily in California. The California Energy Commission is funding the deployment of fueling stations for light-duty FCEVs to support the initial target of deploying 200 stations by 2025, which would be designed to meet the SAE International fueling standard to ensure the safe dispensing of hydrogen into fuel cell light-duty vehicles and a few for the heavy-duty vehicles. Typically, HFSs are supplied with hydrogen via tube trailers, liquid hydrogen tankers, or on-site production. The stations are capable of serving 1,4403,040 fuel cell electric vehicles, which equates to an average capital cost of $\$ 640-\$ 1,600$ per FCEV over the lifetime of these stations. The number-of-vehicle calculations are based on 11,866 miles traveled per year and 61 miles per kg fuel economy, resulting in the hydrogen fuel consumption of $0.533 \mathrm{~kg}$ per day per vehicle. There are 63 larger daily-capacity stations (24-hour fueling capacity of $1000-1,620 \mathrm{~kg}$ ) that are supplied with liquid hydrogen tankers and have four fueling positions, while 48 smaller daily-capacity stations (24-hour fueling capacity of 700-1,000 kg) are supplied with gaseous tube trailers and have two fueling positions. Table 5 lists the costs involved for these stations, including the capital cost and the capital cost normalized according to the daily fueling capacity of the station. An average hydrogen station has a capacity of $1,240 \mathrm{~kg} /$ day (median capacity of $1,500 \mathrm{~kg} /$ day) and requires a capital of approximately $\$ 1.9$ million (median capital cost of $\$ 1.9$ million) [1, 109-111].

Table 5 Capital cost for hydrogen per daily capacity of the hydrogen fueling stations delivered by Liquid hydrogen tankers (LHT).

\begin{tabular}{llll}
\hline Daily Fueling Capacity & $\begin{array}{l}\text { Total Capital Cost } \\
\text { per Capacity }\end{array}$ & $\begin{array}{l}\text { Total Capital Cost } \\
\text { per Capacity } \\
\text { and per Dispenser }\end{array}$ & Total Capital Cost \\
\hline $1,400-1,620 \mathrm{~kg} /$ day & $\$ / 1,200-3,000 \mathrm{~kg} /$ day & $300-740 \$ / \mathrm{kg} /$ day & $1,900-4,200 \$$ \\
\hline
\end{tabular}


Such a network will benefit the DOV and MOV models if the technology succeeds in smoothly correlating the hydrogen flowing out of the reservoir with the fuel cell energy conversion, the parallel battery storage, and the electric alimentation of the vehicle motor. The DOV models accommodate their regular fillings for mobile applications in accordance with the number of hydrogen fueling stations, which are limited in number as of now, although this number is increasing rapidly. The transportation networks are in accordance with large-scale centralized deliveries for collective transports, high-density hydrogen storages, and simplified deliveries correlated to the established hydrogen stations meant for regular loadings that are largely determined by daily demands.

\subsubsection{Hydrogen Tank Systems (HTS)}

Connecting different energy transmission and distribution (T\&D) networks, fuel cells constitute the key technology to efficiently convert hydrogen into electricity for propelling fuel cell-based electric vehicles (FCEVs). Currently, the on-road fuel performance of FCEVs is approximately $1 \mathrm{~kg}$ of hydrogen per $100 \mathrm{~km}$ traveled within the range $\sim 500-1000 \mathrm{~km}$ of a continuous drive. Therefore, FCEVs are capable of providing the mobility service of conventional cars, although with much lower carbon emissions. However, the feasibility of the hydrogen storage technology requires reducing the tank weight and costs and achieving the safety targets that are equivalent or even better than those achieved using the existing gasoline tanks. The currently available commercial hydrogenpowered FCEVs use compressed gas storage, at pressures typically ranging between 350 bar and 700 bar, that have been rigorously tested to meet the automotive performance standards. Several type III and type IV tank systems of higher energy densities (gravimetrically $0.055 \mathrm{~kg} \mathrm{H}_{2} / \mathrm{kg}$ or 1.833 $\mathrm{kWh} / \mathrm{kg}$ and volumetrically $0.026 \mathrm{~kg} \mathrm{H} / \mathrm{L}$ or $0.867 \mathrm{kWh} / \mathrm{L}$ ) are available for automotive applications. Better performances for automotive high-density hydrogen storage have been achieved using cryocompressed vessels. Composite containers, although lighter, are expensive, particularly with an increasing demand for carbon fibers $[109,112]$. The costs of the currently available tank systems vary with the function of the model and the annual tank production expectation. The costs are comparatively lower for the larger models, meant for medium-or heavy-duty vehicles (MDV, $20 \mathrm{~kg}$ $\mathrm{H}_{2}$; HDV, $80 \mathrm{~kg} \mathrm{H}_{2}$ ) such as automobiles, buses, trucks, planes, ships, etc., as the marginal cost of increasing the vessel capacity declines considerably as the vessel size increases [13]. A 10-kg cryogenic $\mathrm{H}_{2}$ system would cost only $30 \%$ higher than a 5-kg system, while it would improve the mass and volumetric efficiency and also reduce the refueling cost. In the vessels with $\mathrm{H}_{2}$ storage of over $8 \mathrm{~kg}$, the additional cost of cryogenic $\mathrm{H}_{2}$ storage could even be less than $\$ 150 / \mathrm{kg} \mathrm{H}_{2}$ [13], limited only by system volume, the chief strength of cryogenic $\mathrm{H}_{2}$ storage. It has been recently estimated that the costs for the large cryo-compressed vessels for buses could be as low as $\$ 10 / \mathrm{kWh}$ when designed for 350 bar [14] and could even be lowered further with the use of MOV models.

The ANL finite element analyses have several requirements for optimal infrastructures. Fuel celldominant architectures were constructed by the DOE for the 700 bar Type 4 vessels. It was concluded that carbon fiber continues to represent over $50 \%$ of the system cost even at high production volumes (100-500 k/year) and that BOP (Balance of Plant) represents $40 \%$ of the system cost at lower production volumes (10 k/year).

The other impediments for heavy-duty vehicles are the volume and shape of their tanks. There are various packaging options to be considered for the available envelope dimensions according to 
the available stored $\mathrm{H}_{2}$ masses on the trucks: frame-mounted (FM), behind the cab (BTC), and roofmounted (RM). Similarly, for the future application of hydrogen technology in the aircraft industry, liquid hydrogen storage is the most promising option, although the specific challenge of storing hydrogen on-board has to be resolved. The hydrogen volume would amount to nearly four times that of the kerosene volume. Currently, aeronautical engineers consider it difficult to store hydrogen in the aircraft wing owing to the cylindrical or spherical form requirements.

The US Department of Energy has listed the following categories of barriers for market expansion A: System Weight and Volume; B: System Cost; C: System Life-Cycle Assessment.

The DOV and MOV models of hydrogen storage systems provide a solution to overcome these barriers. These models are lighter and of malleable shapes, as they operate at lower pressures. Moreover, their costs are reduced by avoiding carbon fibers and interstitial vacuum in the multilayer insulation, which also simplifies their maintenance and increases their life. In these models, the aperture increases safety, and the simplified assemblage further lowers their manufacturing costs.

\section{Author Contributions}

The author did all the research work of this study.

\section{Funding}

This research received no external funding. Institutional Review Board Statement: Not applicable. Informed Consent Statement: Not applicable. Data Availability Statement: Not applicable.

\section{Competing Interests}

Patent: Réservoir Ouvert à Hydrogène, February 4, 2021. France $n^{\circ} 2101075$.

\section{References}

1. Züttel A, Borgschulte A, Schlapbach L. Hydrogen as a future energy carrier. Weinheim, Germany: Wiley-VCH Verlag GmbH \& Co. KGaA; 2008.

2. Berry GD, Aceves SM. The case for Hydrogen in a carbon constrained world. J Energy Resour Technol. 2005; 127: 89-94.

3. Dillich S. Hydrogen storage. Proceedings of the 2009 DOE Hydrogen Program \& Vehicle Technologies Program Merit Review and Peer Evaluation Meeting; 2009 May 18-22; Arlington, Virginia.

4. http://www.eere. energy.gov/hydrogenandfuelcells/mypp

5. Keller JO, Klebanoff L, Schoenung S, Gillie M. The need for hydrogen-based energy technologies in the 21st century. In: Hydrogen storage technology: Materials and applications. Boca Raton, Florida: CRC Press; 2012.

6. Klebanoff L, Keller JO, Fronk M, Scott P. Hydrogen conversion technologies and automotive applications. Hydrogen storage technology: Materials and application. Boca Raton, Florida: CRC Press; 2012.

7. Sinigaglia T, Lewiski F, Santos Martins ME, Siluk JC. Production, storage, fuel stations of hydrogen and its utilization in automotive applications-a review. Int J Hydrog Energy. 2017; 42: 
24597-24611.

8. Abdalla AM, Hossain S, Nisfindy OB, Azad AT, Dawood M, Azad AK. Hydrogen production, storage, transportation and key challenges with applications: A review. Energy Convers Manag. 2018; 165: 602-627.

9. Berry G, Martinez-Frias J, Espinoza-Loza F, Aceves SM. Hydrogen storage and transportation. In: Encyclopedia of energy. Amsterdam, Netherlands: Elsevier Science; 2004.

10. Barthélémy H. Hydrogen storage - industrial prospectives. Int J Hydrog Energy. 2012; 37: 1736417372

11. Bowman B, Klebanoff LE. Historical perspectives on hydrogen, its storage and applications. In: Hydrogen storage technology: Materials and applications. Boca Raton, Florida: CRC Press; 2012.

12. Von Helmolt R, Eberle U. Fuel cell vehicles: Status 2007. J Power Sources. 2007; 165: 833-843.

13. Ciancia A, Pede G, Brighigna M, Perrone V. Compressed hydrogen fuelled vehicles: Reasons of a choice and developments in ENEA. Int J Hydrog Energy. 1996; 21: 397-406.

14. Ahluwalia RK, Peng JK. Automotive hydrogen storage system using cryo-adsorption on activated carbon. Int J Hydrog Energy. 2009; 34: 5476-5487.

15. Klell M. Storage of hydrogen in the pure form. In: Handbook of hydrogen storage. Weinheim, Germany: Wiley-VCH Verlag GmbH \& Co. KGaA; 2010.

16. Setting a World Driving Record with Hydrogen, Salvador Aceves, Science and Technology Review, June 2007, http://www.IInl.gov/str/June07/Aceves.html.

17. Aceves SM, Berry GD, Espinosa-Lo za F, Ledesma-Orozco E, Ross T, Switzer V, et al. Automotive cryogenic capable pressure vessels for compact, high dormancy $\mathrm{LH}_{2}$ storage. Proceedings of the DOE hydrogen and fuel cell annual merit review, Crystal City, Virginia; 2008. Available from: http://www.hydrogen.energy.gov/pdfs/progress08/vii 6 aceves.pdf.

18. Wallner T, Lohse-Busch H, Gurski S, Duoba M, Thiel W, Martin D, et al. Fuel economy and emissions evaluation of BMW hydrogen 7 mono-fuel demonstration vehicles. Int J Hydrog Energy. 2008; 33: 7607-7618.

19. Aceves SM, Espinosa-Loza F, Ledesma-Orozco E, Ross TO, Weisberg AH, Brunner TC, et al. Highdensity automotive hydrogen storage with cryogenic capable pressure vessels. Int J Hydrog Energy. 2010; 35: 1219-1226.

20. Petitpas G, Bénard P, Klebanoff LE, Xiao J, Aceves SM. A comparative analysis of the cryocompression and cryo-adsorption hydrogen storage methods. Int J Hydrog Energy. 2014; 39: 10564-10584.

21. Aceves SM, Petitpas G, Espinosa-Loza F, Matthews MJ, Ledesma-Orozco E. Safe, long range, inexpensive and rapidly refuelable hydrogen vehicles with cryogenic pressure vessels. Int J Hydrog Energy. 2013; 38: 2480-2489.

22. Chahine R, Bose TK. Low-pressure adsorption storage of hydrogen. Int J Hydrog Energy. 1994; 19: 161-164.

23. Poirier E, Chahine R, Bose TK. Hydrogen adsorption in carbon nanostructures. Int J Hydrog Energy. 2001; 26: 831-835.

24. Bénard $\mathrm{P}$, Chahine R. Modeling of adsorption storage of hydrogen on activated carbons. Int J Hydrog Energy. 2001; 26: 849-855.

25. Richard MA, Bénard $P$, Chahine R. Gas adsorption process in activated carbon over a wide temperature range above the critical point. Part 1: Modified Dubinin-Astakhov model. Adsorption. 2009; 15: 43-51. 
26. Stephanie-Victoire F, Goulay AM, de Lara EC. Adsorption and coadsorption of molecular hydrogen isotopes in zeolites. Langmuir. 1998; 14: 7255-7259

27. Xu WC, Takahashi K, Matsuo Y, Kumagai M, Ishiyama S, Kaneko K, et al. Investigation of hydrogen storage capacity of various carbon materials. Int J Hydrog Energy. 2007; 32: 25042512.

28. Weinberger B, Lamari-Darkrim F. High pressure cryo-storage of hydrogen by adsorption at $77 \mathrm{~K}$ and up to $50 \mathrm{MPa}$. Int J Hydrog Energy. 2009; 34: 3058-3064.

29. Lamari-Darkrim F, Malbrunot P, Tartaglia GP. Review of hydrogen storage by adsorption in carbon nanotubes. Int J Hydrog Energy. 2002; 27: 193-202.

30. Rowsell JL, Yaghi OM. Strategies for hydrogen storage in metal-organic frameworks. Angew Chem Int Ed. 2005; 44: 4670-4679.

31. Zhou L, Zhou Y, Sun Y. Enhanced storage of hydrogen at the temperature of liquid nitrogen. Int J Hydrog Energy. 2004; 29: 319-322.

32. Wang $Q$, Johnson JK. Molecular simulation of hydrogen adsorption in single-walled carbon nanotubes and idealized carbon slit pores. J Chem Phys. 1999; 110: 577.

33. Paggiaro R, Polifke W, Bénard P. Cryo-adsorptive hydrogen storage on activated carbon. I: Thermodynamic analysis of adsorption vessels and comparison with liquid and compressed gas hydrogen storage systems. Int J Hydrog Energy. 2010; 35: 638-647.

34. Paggiaro R, Michl F, Bénard P, Polifke W. Cryo-adsorptive hydrogen storage on activated carbon. II: Investigation of the thermal effects during filling at cryogenic temperatures. Int J Hydrog Energy. 2010; 35: 648-659.

35. Ahluwalia RK, Hua TQ, Peng JK, Lasher S, McKenney K, Sinha J, et al. Technical assessment of cryo-compressed hydrogen storage tank systems for automotive applications. Int J Hydrog Energy. 2010; 35: 4171-4184.

36. Paster MD, Ahluwalia RK, Berry G, Elgowainy A, Lasher S, McKenney K, et al. Hydrogen storage technology options for fuel cell vehicles: Well-to-wheel costs, energy efficiencies, and greenhouse gas emissions. Int J Hydrog Energy. 2011; 36: 14534-14551.

37. Hardy B, Corgnale C, Chahine R, Richard MA, Garrison S, Tamburello D, et al. Modeling of adsorbent based hydrogen storage systems. Int J Hydrog Energy. 2012; 37: 5691-5705.

38. DOE Hydrogen and Fuel Cells Program Record 19009 [Internet]. Available from:

https://www.hydrogen.energy.gov/pdfs/19009 h2 production cost pem electrolysis 2019 pdf.

39. Moreno-Blanco JC, Elizalde-Blancas F, Gallegos-Muñoz A, Aceves SM. The potential for avoiding hydrogen release from cryogenic pressure vessels after vacuum insulation failure. Int J Hydrog Energy. 2018; 43: 8170-8178.

40. Moreno-Blanco J, Petitpas G, Espinosa-Loza F, Elizalde-Blancas F, Martinez-Frias J, Aceves SM. The fill density of automotive cryo-compressed hydrogen vessels. Int J Hydrog Energy. 2019; 44: 1010-1020.

41. Petitpas G, Aceves SM. Modeling of sudden hydrogen expansion from cryogenic pressure vessel failure. Int J Hydrog Energy. 2013; 38: 8190-8198.

42. Petitpas G, Aceves SM. The isentropic expansion energy of compressed and cryogenic hydrogen. Int J Hydrog Energy. 2014; 39: 20319-20323.

43. Moreno-Blanco J, Petitpas G, Espinosa-Loza F, Elizalde-Blancas F, Martinez-Frias J, Aceves SM. The storage performance of automotive cryo-compressed hydrogen vessels. Int J Hydrog 
Energy. 2019; 44: 16841-16851

44. Peters ST, Humphrey WD, Foral RF. Filament winding - composite structure fabrication. Covina, CA: SAMPE Publishers; 1991.

45. Roh HS, Hua TQ, Ahluwalia RK. Optimization of carbon fiber usage in Type 4 hydrogen storage tanks for fuel cell automobiles. Int J Hydrog Energy. 2013; 38: 12795-12802

46. Petitpas G, Moreno-Blanco J, Espinosa-Loza F, Aceves SM. Rapid high density cryogenic pressure vessel filling to 345 bar with a liquid hydrogen pump. Int J Hydrog Energy. 2018; 43: 19547-19558.

47. Richardson IA, Fisher JT, Frome PE, Smith BO, Guo S, Chanda S, et al. Low-cost, transportable hydrogen fueling station for early market adoption of fuel cell electric vehicles. Int J Hydrog Energy. 2015; 40: 8122-8127.

48. Alcantar V, Ledesma S, Aceves SM, Ledesma E, Saldana A. Optimization of type III pressure vessels using genetic algorithm and simulated annealing. Int J Hydrog Energy. 2017; 42: 2012520132.

49. Alcantar V, Aceves SM, Ledesma E, Ledesma S, Aguilera E. Optimization of Type 4 composite pressure vessels using genetic algorithms and simulated annealing. Int J Hydrog Energy. 2017; 42: 15770-15781.

50. Pereira AL, Chaves AB, Lerner E. Vapor pressure measurements of para-hydrogen adsorbed on exfoliated graphite. J Low Temp Phys. 1992; 88: 421-431.

51. Nguyen TX, Jobic H, Bhatia SK. Microscopic observation of kinetic molecular sieving of hydrogen isotopes in a nanoporous material. Phys Rev Lett. 2010; 105: 085901.

52. Wilson WA, Weitzel DH. Vapor phase ortho-para conversion in the large CEL-NBS hydrogen liquefier. In: Advances in cryogenic engineering. Boston, MA: Springer; 1960.

53. Weitzel DH, Loebenstein WV, Draper JW, Park OE. Ortho-para catalysis in liquid-hydrogen production. J Res Nat Bur Standards. 1958; 60: 221-227.

54. Wakao N, Smith JM, Selwood PW. The low temperature ortho-hydrogen conversion over supported oxides for parahydrogen conversion and hydrogen-deuterium ewuilibration. J Catal. 1964; 1: 62-73.

55. Schmauch GE, Singleton AH. Technical aspects of ortho-parahydrogen conversion. Ind Eng Chem. 1964; 56: 20-31.

56. Ilisca E. Ortho-para conversion of hydrogen on surfaces. Prog Surf Sci. 1992; 41: 217-335.

57. Kim JH, Kang SW, Nah IW, Oh IH. Synthesis and characterization of Fe-modified zeolite for spin conversion of hydrogen at cryogenic temperature. Int J Hydrog Energy. 2015; 40: 15529-15533.

58. Das T, Kweon SC, Nah IW, Karng SW, Choi JG, Oh IH. Spin conversion of hydrogen using supported iron catalysts at cryogenic temperature. Cryogenics. 2015; 69: 36-43.

59. Kim JH, Karng SW, Oh IH, Nah IW. Ortho-para hydrogen conversion characteristics of amorphous and mesoporous $\mathrm{Cr}_{2} \mathrm{O}_{3}$ powders at a temperature of $77 \mathrm{~K}$. Int J Hydrog Energy. 2015; 40: 14147-14153.

60. Lipman MS, Cheung H, Roberts OP. Continuous conversion hydrogen liquefaction. Chem Eng Prog. 1963; 59: 49.

61. Baker CR, Paul RS. Purification of liquefaction grade hydrogen. Chem Eng Prog. 1963; 59: 61-64.

62. Newton CL. Hydrogen production, liquefaction and use. Cryogen Eng News. 1967; 2: 50-60.

63. Baker CR, Shaner RL. A study of the efficiency of hydrogen liquefaction. Int J Hydrog Energy. 1978; 3: 321-334. 
64. Flynn T. Cryogenic Engineering, revised and expanded. Boca Raton, FL: CRC Press; 2004.

65. Singleton AH, Lapin A. Design of para-orthohydrogen catalytic reactors. Adv Cryogen Eng. 1966; 11: 617-630.

66. Ilisca E. Hydrogen conversion in nanocages. Hydrogen. 2021; 2: 160-206.

67. Fujiwara M, Niki K, Okano T, Fukutani K. Ortho-para conversion of hydrogen molecules on $\mathrm{Cr}_{2} \mathrm{O}_{3}(0001) / \mathrm{Cr}(110)$ surfaces. J Phys Conf Ser. 2010; 200: 22038.

68. FitzGerald SA, Burkholder B, Friedman M, Hopkins JB, Pierce CJ, Schloss JM, et al. Metal-specific interactions of $\mathrm{H}_{2}$ adsorbed within isostructural metal organic frameworks. J Am Chem Soc. 2011; 133: 20310-20318.

69. Si Y, Wang W, El-Sayed EM, Yuan D. Use of breakthrough experiment to evaluate the performance of hydrogen isotope separation for metal-organic frameworks M-MOF-74 ( $\mathrm{M}=\mathrm{Co}$, $\mathrm{Ni}, \mathrm{Mg}$, Zn). Sci China Chem. 2020; 63: 881-889.

70. Zubir NA, Yacou C, Motuzas J, Zhang X, da Costa JC. Structural and functional investigation of graphene oxide $-\mathrm{Fe}_{3} \mathrm{O}_{4}$ nanocomposites for the heterogeneous fenton-like reaction. Sci Rep. 2014; 4: 1-8.

71. Ilisca E. Hydrogen conversion on non-magnetic insulating surfaces. EPL. 2013; 104: 18001.

72. Fukutani K, Sugimoto T. Ortho-para conversion of molecular hydrogen in physisorption states on solid surfaces. Prog Surf Sci. 2013; 88: 279.

73. Boeva OA, Odintzov AA, Solovov R, Ershov BG, Abkhalimov EV, Zhavoronkova KN, et al. Lowtemperature ortho - para hydrogen conversion catalyzed by gold nanoparticles: Particle size does not affect the rate. Int J Hydrog Energy. 2017; 42: 22897-22902.

74. Campbell CT, Lopez N, Vajda S. Catalytic properties of model supported nanoparticles. J Chem Phys. 2020; 152: 140401.

75. Li G, Felser C. Heterogeneous catalysis at the surface of topological materials. Appl Phys Lett. 2020; 116: 070501.

76. Turro NJ, Chen JY, Sartori E, Ruzzi M, Marti A, Lawler R, et al. The spin chemistry and magnetic resonance of $\mathrm{H}_{2} @ \mathrm{C60}$. from the pauli principle to trapping a long lived nuclear excited spin state inside a buckyball. Acc Chem Res. 2010; 43: 335-345.

77. Chae HK, Siberio-Perez DY, Kim J, Go Y, Eddaoudi M, Matzger AJ, et al. A route to high surface area, porosity and inclusion of large molecules in crystals. Nature. 2004; 427: 523-527.

78. Schlichte K, Kratzke T, Kaskel S. Improved synthesis, thermal stability and catalytic properties of the metal-organic framework compound $\mathrm{Cu}_{3}(\mathrm{BTC})_{2}$. Microporous Mesoporous Mater. 2004; 73: 81-88.

79. Eddaoudi M, Kim J, Rosi N, Vodak D, Wachter J, O’Keeffe M, et al. Systematic design of pore size and functionality in isoreticular MOFs and their application in methane storage. Science. 2002; 295: 469-472.

80. Rowsell JL, Millward AR, Park KS, Yaghi OM. Hydrogen sorption in functionalized metal-organic frameworks. J Am Chem Soc. 2004; 126: 5666-5667.

81. Forster PM, Eckert J, Chang JS, Park SE, Srey GF, Cheetham AK. Hydrogen adsorption in nanoporous nickel(II) phosphates. J Am Chem Soc. 2003; 125: 1309-1312.

82. Wiener N. Cybernetics, or control and communication in the animal and the machine. Cambridge, Massachusetts: MIT Press; 2019.

83. Elgowainy A, Mintz $M$, Kelly B, Hooks $M$, Paster $M$. Optimization of compression and storage requirements at hydrogen refueling stations. Proceedings of the ASME 2008 Pressure Vessels 
and Piping Conference; 2008 July 27-31; Chicago, Illinois, USA.

84. Mayer T, Semmel M, Guerrero Morales MA, Schmidt KM, Bauer A, Wind J. Techno-economic evaluation of hydrogen refueling stations with liquid or gaseous stored hydrogen. Int J Hydrog Energy. 2019; 44: 25809-25833.

85. Gursu S, Lordgooel M, Sherif SA, Veziroglu TN. An optimization study of liquid hydrogen boiloff losses. Int J Hydrog Energy. 1992; 17: 227-236.

86. Gursu S, Sherif SA, Veziroglu TN, Sheffield JW. Analysis and optimization of thermal stratification and self-pressurization effects in liquid hydrogen storage systems. J Energy Resour Technol. 1993; 115: 221-231.

87. Emmans $M$, Mori D, Krainz G. Analysis of back gas behaviour of an automotive liquid hydrogen storage system during refilling at the filling station. Int J Hydrog Energy. 2007; 32: 1961-1968.

88. Peschka W. Hydrogen liquefaction. In: Liquid hydrogen. Vienna: Springer; 1992.

89. Staats WL. Analysis of a supercritical hydrogen liquefaction cycle. Cambridge, Massachusetts: Massachusetts Institute of Technology; 2008.

90. Schwartz J. Advanced hydrogen liquefaction process. Proceedings of the DOE Annual Merit Review Meeting; 2011 May 10; Praxair-Tonawanda, NY.

91. Yanxing Z, Maoqiong G, Yuan Z, Xueqiang D, Jun S. Thermodynamics analysis of hydrogen storage based on compressed gaseous hydrogen, liquid hydrogen and cryo-compressed hydrogen. Int J Hydrog Energy. 2019; 44: 16833-16840.

92. Abe JO, Popoola AP, Ajenifuja E, Popoola OM. Hydrogen energy, economy and storage: Review and recommendation. Int J Hydrog Energy. 2019; 44: 15072-15086.

93. Milenko YY, Sibileva RM, Strzhemechny MA. Natural ortho-para conversion rate in liquid and gaseous hydrogen. J Low Temp Phys. 1997; 107: 77-92.

94. Matthews MJ, Petitpas G, Aceves SM. A study of spin isomer conversion kinetics in supercritical fluid hydrogen for cryogenic fuel storage technologies. Appl Phys Lett. 2011; 99: 081906.

95. Petitpas G, Aceves SM, Matthews MJ, Smith JR. Para-H2 to ortho-H2conversion in a full-scale automotive cryogenic pressurized hydrogen storage up to 345 bar. Int J Hydrog Energy. 2014; 39: 6533-6547.

96. Weitzel DH, Van Valin CC, Draper JW. Design data for ortho-parahydrogen converters. Adv Cryog Eng. 1957; 3: 73-84.

97. Hutchinson HL. kinetics study of the para-ortho shift of hydrogen. Boulder, Colorado: University of Colorado Boulder; 1964.

98. Hust JG, Stewart RB. A Compilation of the Property Differences of Ortho and Para Hydrogen or Mixtures of Ortho and Para Hydrogen. Boulder, CO: National Bureau of Standards; 1965; 8812.

99. Hutchinson $\mathrm{HL}$, Barrick PL, Brown LF. Experimental study of reaction kinetics for paraorthohydrogen at $20^{\circ}$ to $80^{\circ} \mathrm{K}$. Adv Cryog Eng. 1965; 10: 190-196.

100. Barrick PL, Brown LF, Hutchinson HL, Cruse RL. Improved ferric oxide gel catalysts for orthoparahydrogen conversion. Adv Cryog Eng. 1965; 10: 181-189.

101.Zhou D, Sullivan NS. Efficient ortho hydrogen to para hydrogen conversion. Proceedings of the American Physical Society March Meeting; 2004 March 22-26; Quebec, Canada.

102. Ionex ${ }^{\circledR}$ - Type O-P Catalyst Hydrous Ferric Oxide [Internet]. Available from: https://www.molecularproducts.com/wp-content/uploads/2017/03/166 Rev-C TechnicalDatasheet OP-Catalyst.pdf.

103. Farkas A. Orthohydrogen, parahydrogen and heavy hydrogen. Cambridge, UK: Cambridge 
University Press; 1935.

104. Haar L, Friedman AS, Beckett CW. Ideal gas thermodynamic functions and isotope exchange functions for diatomic hydrides, deuterides, and tritides. Gaithersburg, Maryland: National Bureau of Standards; 1961.

105. Leachman JW, Jacobsen RT, Penoncello SG, Lemonn EW. Fundamental equation of state for para hydrogen, normal hydrogen and orthohydrogen. J Phys Chem Ref Data. 2009; 38: 721-748.

106.Ahluwalia RK, Peng JK, Roh HS, Hua TQ, Houchins C, James BD. Supercritical cryo-compressed hydrogen storage for fuel cell electric buses. Int J Hydrog Energy. 2018; 43: 10215-10231.

107. Rivard E, Trudeau M, Zaghib K. Hydrogen storage for mobility: A review. Materials. 2019; 12: 1973.

108. Hydrogen [Internet]. Paris, France: IEA; 2021. Available from: https://www.iea.org/fuels-andtechnologies/hydrogen.

109. Hydrogen fueling stations cost [Intenet]. U.S. Department of Energy; 2020. Available from: https://www.hydrogen.energy.gov/pdfs/21002-hydrogen-fueling-station-cost.pdf.

110.Ghorbani R, Behrangi S, Aghajani H, Taghizadeh Tabrizi A, Abdian N. Application of synthesized porous 3D graphene structure for electrochemical hydrogen storage. Mater Sci Eng B. 2021; 268: 115139.

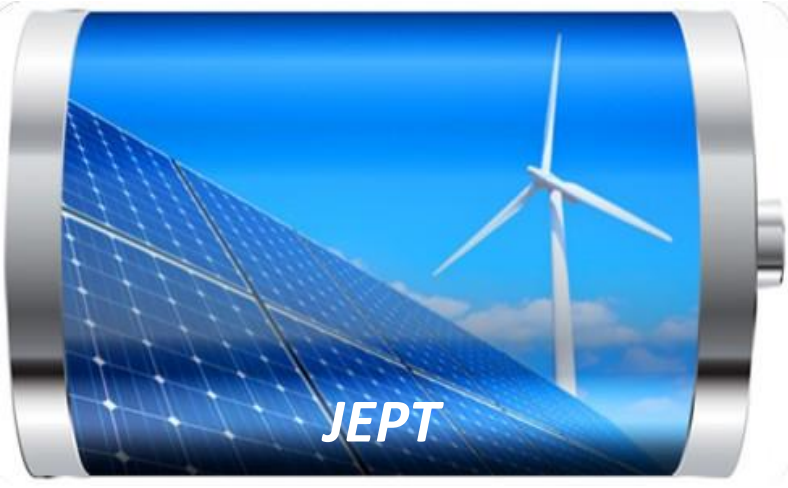

Enjoy JEPT by:

1. Submitting a manuscript

2. Joining in volunteer reviewer bank

3. Joining Editorial Board

4. Guest editing a special issue

For more details, please visit: http://www.lidsen.com/journal/jept 